Alma Mater Studiorum - Università di Bologna DEPARTMENT OF ECONOMICS

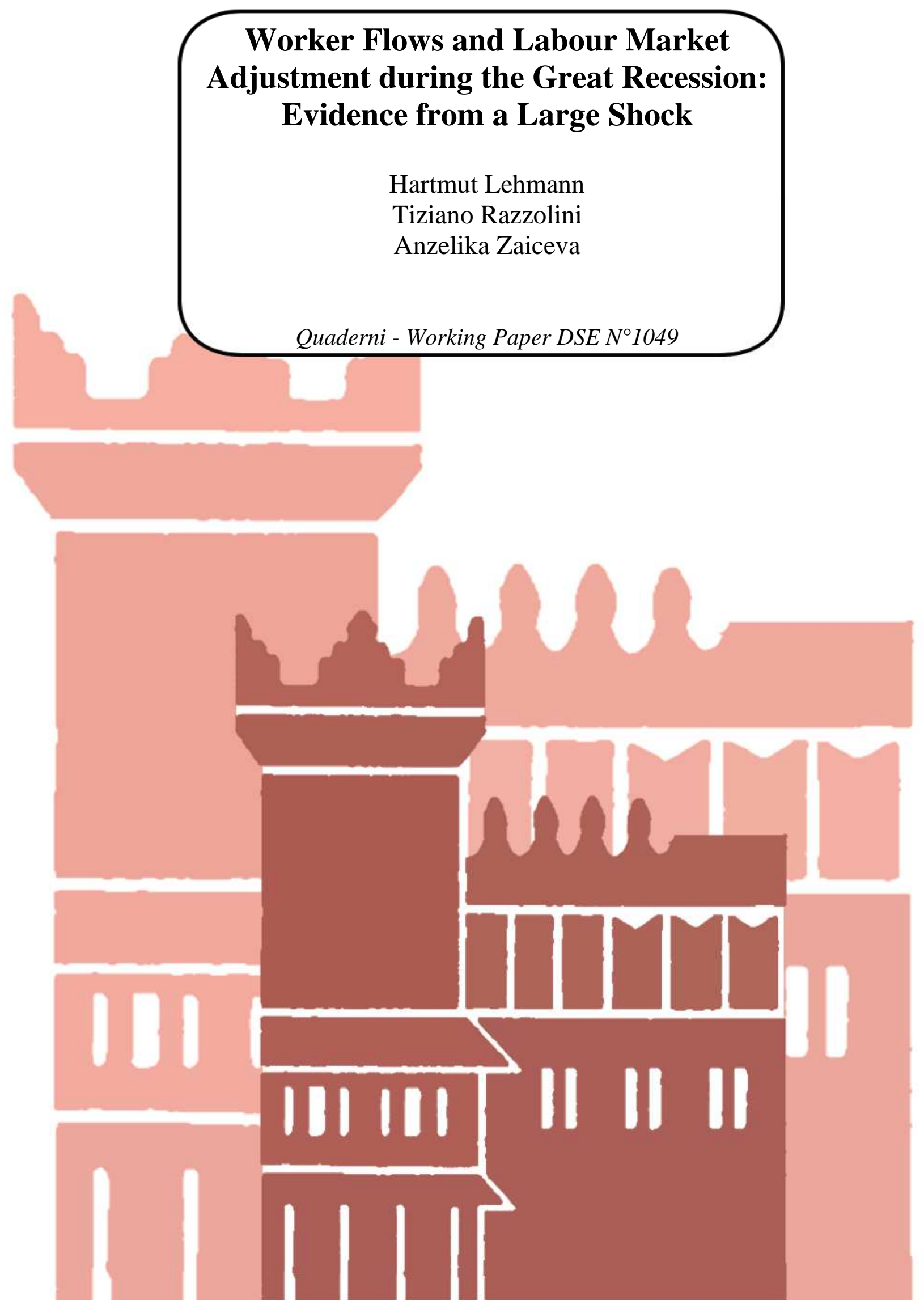




\title{
Worker Flows and Labour Market Adjustment during the Great Recession: Evidence from a Large Shock*
}

\author{
Hartmut Lehmann (University of Bologna, IZA and DIW) \\ Tiziano Razzolini (University of Siena and IZA) \\ Anzelika Zaiceva (University of Modena and Reggio Emilia and IZA)
}

\begin{abstract}
This paper analyzes how the labor market adjusts to the Great Recession. To this aim, we use the data for Latvia, a country that has experienced one of the most severe recessions in Europe and a subsequent remarkable recovery. Employing longitudinal EU SILC data and a panel data set constructed by us from various waves of the Latvian Labour Force Survey (LLFS), we estimate worker transitions between labor market states. Labor market adjustment takes place predominantly at the extensive margin since it is driven by flows from permanent wage employment to unemployment. We also show that older, non-Latvian and above all less skilled workers are especially hard hit by the economic crisis. Estimated transitions between four mutually exclusive occupational groups demonstrate that downward mobility is very limited even during the Great Recession. Finally, wage regressions suggest that job mobility is not associated with increased labour productivity during and immediately after the crisis.
\end{abstract}

JEL Classification: J6, J21, P20, P23.

Keywords: Labour market transitions, job and occupational mobility, Great Recession, Latvia.

\footnotetext{
*An early version of this paper was written as a background paper for the OECD Latvia Accession Report. We are grateful to Paolo Falco, Mihails Hazans, Herwig Imervoll, Artjoms Ivlevs and Andreas Wörgötter for valuable comments. We thank Georgios Tassoukis and the IZA IDSC for help with the Latvian Labour Force Survey data. Neither the OECD nor its member countries are responsible for the content of the paper.
} 


\section{Introduction}

The 2008 economic crisis has brought about many challenges for economies and labour markets. A profound deterioration of the main economic indicators reflected the deepest recession over the last decades in many countries. One of the most important questions that need to be addressed is how the labour market adjusts to such large economic shocks. In this paper, we use data from Latvia that experienced arguably the largest shock in Europe to estimate the impact on worker flows during the Great Recession.

Latvia joined the European Union (EU) in 2004 and the Eurozone in 2014. Until the world financial crisis the Latvian economy experienced high annual GDP growth rates and enjoyed low unemployment. Combined with high out-migration after the accession to the EU, labour shortages became important. During the Great Recession Latvia experienced the largest unemployment rate among the new EU members, comparable to that in the Southern EU countries, and had, together with two other Baltic States, Lithuania and Estonia, the largest decline in GDP growth. The recovery, however, was also remarkable. While with the onset of the crisis GDP growth turned strongly negative, reaching $-19.1 \%$ on an annual basis in the third quarter of 2009 , this strong negative trend was soon overturned, with GDP growing at positive rates from the third quarter of 2010 onwards (see Figure 1). Since 2010 Latvia is one of the best performers in the EU with regards to GDP growth. Regarding unemployment, while it has been increasing and is still high in Southern EU countries, it has been declining steadily in Latvia.

How does the labour market adjust to this strong variation in economic activity? Which parts of the workforce are particularly affected during the downturn? These are the questions we analyse in this study, exploring also whether the dramatic cycle that we observe between 2007 and 2011 left longer lasting traces in the Latvian labour market. 
One way to analyse labour market adjustment during the Great Recession is to look at transitions between labour market states and their determinants. ${ }^{1}$ To this aim, we employ both the EU SILC and Latvian Labour Force Survey data over the period 2007 to 2011/12. The longitudinal EU SILC data allows us to estimate transitions between three standard labour market states, employment, unemployment and inactivity, as well as transitions between six states, namely permanent employment, temporary employment, professional self-employment, non-professional self-employment, unemployment and inactivity. Following La Porta and Shleifer (2008), our measure of non-professional self-employment can be taken as a proxy for informal self-employment and is thus based on one of the "productivity" definitions of informal employment used by the ILO. However, this has to be interpreted with caution, since we do not know to which extent nonprofessional self-employment is informal. We complement this analysis by estimating transitions between four classes of aggregated occupations, which give us a hunch about the importance of upward and downward mobility in the Latvian labour market. Finally, in order to see whether mobility leads to more productivity, we estimate wage regressions that include dummies, which capture movements between jobs, the level of occupational groups and their interactions. When employing the Latvian Labour Force Survey (LLFS), we construct a panel data set to estimate transitions between the three standard labour market states, employment, unemployment and inactivity. $^{2}$

Our main results indicate that labour market adjustment takes place predominantly at the extensive margin since it is driven by flows from permanent wage employment to unemployment. It is important to note that out-migration played also a very important role. Without the option to emigrate the unemployment rate would have been even higher (Hazans, 2013). While we do not directly analyze emigration and its effects on the labour market in this paper, we discuss the impacts

\footnotetext{
${ }^{1}$ The study by Bellmann et al. (1995) on Eastern Germany is the first paper that looks at transitions between labour market states in a then transition economy subject to a transition shock.

${ }^{2}$ Fadajeva and Krasnopjorovs (2015) provide complementary firm level evidence on labour market adjustment during 2008 to 2013 in Latvia.
} 
of out-migration in the subsequent sections. ${ }^{3}$ We also show that older, non-Latvian and above all less skilled workers are especially hard hit by the economic crisis. Estimated transitions between four occupational groups demonstrate that downward mobility is very limited even during the Great Recession. Finally, estimating wage regressions we find that job mobility is not associated with increased labour productivity.

The rest of the paper is structured as follows. Section 2 presents economic and labour market conditions in Latvia during and after the Great Recession, Section 3 defines the data and discusses construction of transitions between labour market states. We calculate transitions and estimate transition probabilities and their determinants in Section 4, while wage changes associated with transitions are analysed in Section 5. Section 6 provides conclusions and policy implications.

\section{The economic crisis and the labour market in Latvia}

Since the beginning of this century Latvia has enjoyed solid economic growth and declining unemployment as a result of structural reforms undertaken in the country during its transition from a socialist to a market economy in the 1990s. Combined with relatively high emigration after the accession to the EU in 2004, which has contributed to, but was not the only factor behind declining unemployment, labour shortages emerged in 2005-2007 (Hazans and Philips, 2010; Rutkowski, 2007).

The economic crisis has had a profound impact on the country's economy and the labour market. As Figure 2 illustrates, Latvia, together with the two other Baltic states, Estonia and Lithuania, experienced the largest decline in GDP among European countries in 2009. This strong negative trend was, however, soon overturned, with GDP growing at positive rates from late 2010 onwards, thus making Latvia one of the best performers in the EU with regards to GDP growth after

\footnotetext{
3 A detailed analysis of Latvian emigration and its impacts is available in Hazans $(2013,2016)$, while Zaiceva and Zimmermann (2016) analyze return migration during the crisis in the new EU member states.
} 
the Great Recession (see Figure 2). Mirroring the negative trends in GDP growth, unemployment increased significantly in Latvia. As Figure 3 illustrates, it has reached $19.5 \%$ in 2010 and was the highest among the new EU member states and the second largest in the whole EU after Spain, where unemployment reached $20.1 \%$. Remarkably, however, while unemployment continued to increase in the Southern EU countries, it has been declining steadily thereafter in Latvia to $11.9 \%$ in 2013, significantly lower than in Southern Europe and also lower than in Ireland, Slovakia and Bulgaria. Importantly, also the youth unemployment rate after having increased to more than $26 \%$ in 2010 has been declining thereafter, in contrast to the trends in Southern EU countries and several new member states. However, both the unemployment rate and the youth unemployment rate remain significantly higher than their pre-crisis levels.

The post-accession period for Latvia was characterized also by relatively high outmigration, which increased even more during the crisis. In general, migration provides an important adjustment mechanism in a single currency area. Several recent studies confirm that migration reacts to the deterioration of relative economic conditions. For example, Bertoli et al. (2013) find evidence of "migration diversion" into Germany during the crisis, a country which performed exceptionally well, while Elsner and Zimmermann (2016) show that migration from the new EU member states to Germany has increased substantially despite migration restrictions that Germany applied to these countries until 2011, and was similar to an increase in migration from Southern EU countries. Hazans (2013) shows that net emigration from Latvia has increased remarkably during the crisis, particularly to the UK, the most important destination country, while it became negative for Ireland (Table 4.3, p. 71). An earlier paper by Ivlevs et al (2009) also documents that emigration to the UK has increased in the early period of the crisis from those countries that experienced the largest economic downturn.

Figure 5 plots migration inflows to the UK, measured by the National Insurance Numbers (NINos) allocated to adult overseas nationals entering the UK. It indicates that emigration to the UK has increased substantially from Latvia and Lithuania, countries hit particularly hard by the crisis, 
with emigration levels even surpassing the post-accession levels. Is there a relation between labour market conditions at home and migration? A simple theoretical model suggests that migration depends on the relative wages between home and host countries weighted by the probability to find employment. Figure 6 plots simple correlations between unemployment and emigration to the UK for Latvia and for all new EU members, suggesting a strong positive relation. Indeed, the share of unemployed among all Latvian migrants (i.e. whose whose last registered activity before leaving was unemployment) has increased from 10\% in 2005 to $48 \%$ in 2011 (Hazans, 2013). Overall, the available literature suggests that emigration from Latvia has contributed to a decrease of unemployment and without the option to emigrate unemployment would have been even higher (ibidem). In the analysis that follows, due to data limitations, we unfortunately are not able to include emigration. Indeed, emigration potentially could constitute an additional labour market state in our presented transition matrices. Nevertheless, we attempt to at least proxy potential emigration by looking at panel attrition. When out-migration, which we proxy with panel attrition, is not systematically correlated with the estimated labour market transitions, the presented adjustment trends over the Great Recession and in its aftermath remain credible. But as we show below, attrition hardly affects the estimated transitions at all.

\section{Data, definitions and the sample}

In the EU SILC data labour market status refers to the self-defined current economic status. In particular, when analysing six labour market states the labour force status is generated as follows. For permanent (EP) and temporary (ET) employees and self-employed and family workers (ESF) the variable "employment status" was used. Self-employed and family workers are further disaggregated into professional (ESFP) and non-professional (ESFNP), where professional refers to occupation groups 1-3 in ISCO-88. For unemployed (U) and inactive $(\mathrm{N})$ the information on selfdefined "current economic status" was used. Labour force status is set to missing if both 
employment status and current economic status are missing. The results have to be interpreted with caution due to the very small number of observations in several categories.

Regarding the Latvian labour force survey (LLFS), it has several advantages relative to the EU SILC. First, labour market status, i.e., employment, unemployment or inactivity, is not selfreported but constructed from the information available in the data using the conventional ILO definitions. ${ }^{4}$ It also contains information on ethnicity ${ }^{5}$ and sector of employment. In addition, we construct a regional variable for the labour market in the capital region (Riga and Pieriga) and in the rest of the country. Using the LLFS, the panel was constructed as follows. Only individuals who appear in two consecutive years and have no missing values in the current and lagged labour market status are retained in the sample. In addition, we only keep transitions between two different interviews in two consecutive years with at least 52 weeks of distance (92\% are exactly at 52 weeks of distance, there remaining $8 \%$ between 53 and 65 ). With this criterion we discard only $1.4 \%$ of individuals. Note that sometimes for the same individual there are two possible transitions across two consecutive years: that is, the transition between the first and third interview, and the transition between the second and fourth interview. Both transitions occur with 52 weeks /one year of distance or slightly more. In these cases we use all transitions but implement some reweighting: for instance, to an individual with two possible transitions in the same year (e. 2007/2008) we assign weights

\footnotetext{
${ }^{4}$ There exists also information on self-reported past labour market status given by the reference person for all members of the household. This information could in principle be used to construct transitions. Because of potentially large measurement error we do not use this information.

${ }^{5}$ To define ethnicity we have used a variable "Ethnicity" available in the LFS, that distinguishes between Latvian and non-Latvian ethnicity, where the latter group includes above all the following ethnicities: Russian, Belarusian, Ukrainian, Polish, Lithuanian, Jewish, Roma, Estonian and German. We didn't use the citizenship variable, since the choice of citizenship particularly in the case of Latvia is endogenous and the number of non-citizens is large. The definition of a particular category of non-citizens of Latvia is as follows: "Non-citizen of Latvia is a person, who in accordance with the Law "On the Status of Those Former Soviet Union Citizens, Who do not Have Latvian or Other Citizenship" has the right to receive a non-citizen passport of Latvia." It is important to note that non-citizens apart from not having standard civil rights such as voting, cannot enjoy free movement with other EU countries. In the dataset three citizenship categories are available: citizens of Latvia, citizens of EU countries and a third category that combines non-citizens, citizens of non-EU countries and stateless persons.
} 
equal to 0.5 to each of the two transitions. If only one transition is available we assign a weight equal to one. ${ }^{6}$

\section{Transitions between labour market states}

\subsection{Transitions between employment, unemployment and inactivity and their determinants}

Our analytical approach follows Clark and Summers (1979) and Bellmann, Estrin, Lehmann and Wadsworth (1995) in assuming that transitions between labour market states are governed by a Markov process. Having the states of employment (E), unemployment (U) and inactivity (N), we have nine potential transitions, which can be represented by the following matrix $P_{k}$ :

$$
P_{k}=\left[\begin{array}{lll}
E E_{k} & E U_{k} & E N_{k} \\
U E_{k} & U U_{k} & U N_{k} \\
N E_{k} & N U_{k} & N N_{k}
\end{array}\right]
$$

where $U E_{k}$, for example, represents the probability of individual $\mathrm{k}$ being employed in period $\mathrm{t}$ conditional on being unemployed in period $\mathrm{t}-1$. The gross probability of transition from state $\mathrm{i}$ to state $\mathrm{j}$ can be written as:

$$
P_{i j}=\frac{F_{i j}}{S_{i}}, \quad i, j=e, u, n
$$

where $F_{i j}$ is the number of persons flowing from state $\mathrm{i}$ in period $\mathrm{t}-1$ to state $\mathrm{j}$ in period $\mathrm{t}$ and $S_{i}$ is the number of persons in the origin stock in period $t$ - 1. Finally, under Markovian assumptions duration of state occupancy is exponentially distributed and given by the reciprocal of the outflow rate:

\footnotetext{
${ }^{6}$ We also drop observations with inconsistencies in the sequence number (e.g., the sequence number changes across waves or individuals with the same sequence number change gender or age category). The number of such cases, however, is small accounting roughly for $2 \%$ of all observations.
} 


$$
\frac{1}{\sum_{j} P_{i j}}, j \neq i
$$

Table 1 shows the estimated annual transitions based on equation 2 and employing the EU SILC data. This table suggests a substantive difference between these transitions for the period 2008 to 2009 and the other years. The former period is precisely the time interval when the crisis has a major impact on the Latvian labour market. Comparing the employment-unemployment $(E U)$ columns of the last year before the crisis and of the period 2008-2009 we see a tripling of the flows from employment to unemployment. We can assume that this dramatic increase is mainly due to labour shedding and not due to voluntary quits.

Disaggregating by gender gives the striking result that it is males who are much more affected by this increase in labour shedding since women's transition rate from employment to unemployment is much lower in the crisis period. Whether slicing the data by age or by educational attainment we get very big jumps in the transition rates for young workers and workers with only primary education. However, all age and educational groups experience very large increases in the flows from employment to unemployment and the relative rankings in the transitions do not change after the onset of the crisis. Males, young workers and workers with only primary education have the highest transition rates from employment into unemployment throughout the analysed period. In the years 2009 - 2010 and 2010 - 2011 the outflows from employment to unemployment are somewhat attenuated relative to the crisis period, but they do not return to the levels of the period 2007 - 2008 as far as the total sample and the sub-groups are concerned. Consequently, we can moot that there is more labour shedding for all the reported years after the crisis than for the period before the crisis.

To see what happens to the unemployed we need to inspect columns $4-6$ in Table 1 . Applying equation 3, one important statistic is the average duration of unemployment which is given by the reciprocal of the sum of the transition probabilities UE and UN. In the pre-crisis period this expected duration is $(1 / 0.551)=1.8$ years while in the periods following the crisis it is $2.2,2.1$ 
and 1.96 years respectively. So, on the measure of the average duration of unemployment the situation does not deteriorate much during the crisis and in its aftermath. We also see, though, that in the period 2010- 2011 outflow rates into employment are at least as high as before the crisis. The slightly longer average durations of unemployment come about because of a fall into the outflow rates into inactivity relative to the pre-crisis years. However, a slightly deteriorating outflow rate in combination with a large inflow rate into unemployment in the aftermath of the crisis implies the build-up of the stock of long-term unemployed that we also find in our companion paper (Lehmann et al., 2015).

Inspection of the disaggregated outflow rates into employment (UE) enables us to determine which groups have particularly large difficulties in leaving unemployment for new jobs. Workers with primary education have a substantially worse experience than their better educated counterparts. In addition, older workers (55-64 years of age) have relative difficulties to find employment, while their transition rates into inactivity are particularly large. What is also very striking is the far higher female outflow rate into employment relative to the male rate. So, in the crisis period 2008 to 2009 male workers have a far worse labour market experience than their female counterparts. As women also have a higher outflow rate into inactivity in this period the average duration of unemployment for men (2.72 years) is roughly one year longer than the average duration for women (1.75 years).

On the basis of the estimated transition matrices we can also state that the main adjustment of the Latvian labour market to the negative shocks in connection with the Great Recession occurred between 2008 and 2010. In the last period for which we have estimates $(2010-2011)$ we see substantial improvements. We have lower outflow rates from employment into unemployment for the whole sample as well as for all sub-categories but one relative to the period $2008-2010$. The same pattern holds for the UE flows: in the period 2010 - 2011, the outflow rates from unemployment into employment are substantially larger than in the previous two periods. 
We next report transition rates between the three labour market states using data from the Latvian labour force survey. The first row in the yearly panels of table 2 reports the transition probabilities for the whole sample. We see patterns across the years that are quite similar to the transition probabilities reported with the EU SILC panel data. In the pre-crisis period 2007 to 2008 we see little labour shedding from employment and substantial flows from unemployment into employment. During the years of main impact of the crisis on the Latvian labour market (2008 to 2009) outflows from employment to unemployment more than double to roughly 10 percent while hirings from unemployment are approximately halved. We also see that outflows from employment into unemployment (EU) fall back to roughly pre-crisis levels as of 2010. Hires from the stock of the unemployed (UE), on the other hand, although they increase in relation to the crisis period do not recover to pre-crisis levels. This might be related to the build-up of long-term unemployment over the crisis with the incidence rising from $34 \%$ before the crisis to $54 \%$ in 2012 . As shown by Layard et al. (1991) with a larger incidence of long-term unemployment overall outflows from unemployment into employment will be reduced since the long-term unemployed have usually great difficulties to leave unemployment for jobs. Finally, looking at the overall flows in the first two panels of table 2 we find that inactivity is not the state that absorbs the shock in connection with the crisis. Outflows from employment and unemployment into inactivity hardly differ between the two periods. In contrast, outflows from employment and from inactivity into unemployment rise sharply from 2007-2008 to 2008-2009. Thus, it is clearly unemployment that absorbs most of the shock brought on by the crisis.

Slicing the data by gender we find that in $2008-2009$ male workers have a probability to lose their jobs that is twice as high as for their female counterparts. Throughout the reported years male workers have larger outflows from employment than female workers but the difference is small for the non-crisis years. ${ }^{7}$ On the other hand, flows from unemployment into employment are very similar across gender for all reported years. As one expects, women leave the labour force at

\footnotetext{
${ }^{7}$ Whether these differences across gender are statistically significant will be established with the MNL estimates of the transitions between labour market states.
} 
larger rates than men throughout the reported years. It is, however, striking that the difference in female and male outflow rates is reduced in the crisis years and that the female outflow rates are lower in the crisis period than before the crisis. Hence, women do not respond to the crisis by exiting from the labour force at an increased rate. Finally, some interesting geographic patterns emerge. Splitting the country into two parts (the capital city of Riga plus surroundings and the rest of the country) we see little difference in labour market adjustment across the two regions for the first four reported periods. Only in the period 2011 - 2012 are outflows from employment into unemployment substantially larger in the rest of the country than in metropolitan Riga, while outflows from unemployment into employment are 6 percentage points larger in Riga than in the rest of the country. Thus, one might infer that the metropolitan labour market of Riga recovers somewhat better from the crisis than the labour markets in the rest of the country.

The determinants of the transitions from the respective origin state to the respective destination states are estimated with a multinomial logit (MNL) model. We present the marginal effects of a variable on the transition probabilities into a specific state. We also report the effect of a variable on the "transition probability" of remaining in the origin state. For example, table 3 shows employment as the origin state and the marginal effects of a large set of variables on the transition probabilities from $\mathrm{E}$ to $\mathrm{E}$ (E-E), from $\mathrm{E}$ to $\mathrm{U}(\mathrm{E}-\mathrm{U})$ and from $\mathrm{E}$ to $\mathrm{N}(\mathrm{E}-\mathrm{N})$. By construction the marginal effects add up to zero. The marginal effects show the impact of a single variable on the transition probability of interest, holding all other factors constant.

With employment as the origin state in table 3, where we control for sector and occupation, men have a slightly higher likelihood to flow into unemployment and a slightly lower probability to leave the labour force, amounting to roughly half a percentage point in both cases, than their female counterparts. Workers residing in the metropolitan Riga region have lower probabilities of a similar magnitude to enter unemployment and flow into inactivity. Relative to the marginal effects of the other demographic factors shown, the gender and regional effects are, however, quite small. Age certainly plays a bigger role than gender and region in the estimates since the core age group has 
roughly a 1.5 percentage points lower probability to flow into unemployment and into inactivity than workers until the age of 24 . The probabilities of older workers are -3.4 and 2.2 percentage points respectively when considering transitions into unemployment or into inactivity. Latvian workers also have a somewhat better labour market experience than non-Latvians since their proclivity to enter unemployment is about 1 percentage point lower than that of non-Latvians. Finally workers with upper secondary and in particular with tertiary education have substantially lower likelihoods to enter unemployment and to leave the labour force than less educated workers. The marginal effects linked to sectors on transitions to unemployment are especially large. In particular, workers in construction have a probability of leaving for unemployment that is nearly 7 percentage points higher than the probability for workers in agriculture and fishery. Other sectors where workers disproportionally lose jobs are real estate, trade, accommodation and food services and mining and manufacturing. As far as occupations are concerned we find service workers, craft workers and workers in elementary occupations having a relatively high likelihood to flow into unemployment. Overall, it is workers with lower skills who are particularly affected by job loss.

The MNL estimates of transitions from unemployment show some interesting patterns (table 4). Male workers have a higher likelihood to remain unemployed only because they are less likely to enter inactivity than female workers, while flows into employment do not show any statistically significant difference. In contrast, unemployed workers residing in Riga and surroundings have a probability of entering employment that is roughly 4 percentage points higher than that of unemployed workers residing elsewhere. Age is also an important determinant of flows out of unemployment. The core age group has a substantially higher chance to find employment than other age groups and a much lower likelihood to flow from unemployment to inactivity. Older workers, on the other hand, have lower flows into employment and larger flows into inactivity than the rest of the workforce. Ethnicity is an important determinant of transitions out of unemployment since Latvian workers leave unemployment at a significantly higher rate than non-Latvians because of a much higher transition rate to employment. These result that ethnic minorities have a worse 
performance than the majority in terms of employment are in line with previous findings for Latvia (Hazans 2010, 2011a, 2013). Finally, it comes as no surprise that better educated workers have higher accession rates to jobs and lower transition rates into inactivity.

In table 5 we report the marginal effects of the determinants of transitions out of inactivity. Male workers have a higher proclivity to enter the labour force, and this through entry into both employment and unemployment. While residence has no impact on flows out of inactivity, age and educational attainment are very important determinants of these flows. Workers in the core age group have higher flows into both employment and unemployment while older workers remain disproportionally inactive because of much lower flows into employment. Workers with upper secondary and tertiary education have much higher transition rates into employment than their less educated colleagues. Finally ethnicity also plays a role since Latvians access jobs at a rate that is 2 percentage points higher than the job accession rate of non-Latvians. The effect is, however, minor since both education and age exhibit substantially larger marginal effects than ethnicity.

One issue that needs to be tackled is attrition, out-migration being one of the potential reasons for it. The selective out-migration and attrition might bias our results if the flow of persons who drop out of the survey is correlated systematically with the transitions between labour market states. Respondents are interviewed at most four times in two consecutive years, for example, in the $1^{\text {st }}$ quarter $2007,2^{\text {nd }}$ quarter $2007,1^{\text {st }}$ quarter 2008 and $2^{\text {nd }}$ quarter 2008 . As this interview structure shows, the distance between the first and third interview is one year. Since we estimate annual transition probabilities we can define future attriters as respondents who appear in the first three interviews but are not present in the fourth interview. We perform separate regressions (with the same covariates as in tables 3 to 5) where the transitions are restricted to the flows between interview 1 and 3 and where we add an attrition dummy for those who have no fourth interview. The coefficient estimates of the attrition dummy are reported in the last e row in tables 3 to 5 . 
The important result regarding the coefficient estimates on the attrition dummy in Table 3 is that flows from employment into unemployment are slightly over-estimated when we concentrate on the sample of non-attriters. However, this effect is quite small as a comparison of the marginal effects of the other covariates and the coefficient on the attrition dummy shows. Table 4, on the other hand, shows that attrition, as modelled by us, does not bias the flows from unemployment into employment, while concentrating on non-attriters does over-estimate exiting the labour force from the state of unemployment by roughly 5 percentage points. Finally, flows from inactivity into employment (unemployment) are slightly under-estimated (over-estimated) when we ignore attrition (see Table 5). We should also mention that adding the attrition dummy to the set of covariates does not change the coefficient estimates on the other covariates in any discernible way. This exercise leads us to conclude that attrition does not seem to strongly affect the transitions from employment and unemployment and that the large flows between labour market states that we find during the Great Recession are certainly not driven by attrition.

\subsection{Six labour market states: transitions and determinants}

In this sub-section we return to the EU SILC data and disaggregate employment into four mutually exclusive states: permanent wage employment, temporary wage employment and professional and non-professional self-employment. The four employment states are defined using the variable employment status in the data set, while unemployment and inactivity are derived from the selfdefined current economic status given in the data. Labour market status was set to missing if both employment status and current economic status were missing.

Professional self-employment refers to self-employed workers who are legislators, senior officials, managers, professionals and associated professionals (i.e., occupation categories $1-3$ of ISCO-88). Non-professional self-employment includes also family workers. Following La Porta and Shleifer (2008) we could take non-professional self-employment as a proxy for informal employment. While in developing countries this might be a relatively precise proxy, it is not 
entirely clear whether this precision is given in the Latvian context. For example, Lehmann and Pignatti (2007) find the overlap of non-professional self-employment and informal self-employment in Ukraine to be rather small. We, therefore, speak here of non-professional self-employment having in mind that there might be some overlap with informal self-employment. ${ }^{8}$

Before we discuss estimated transitions between the six labour market states we present the marginal effects of multinomial logit estimates of the probability of finding oneself in one of these states. We thus establish which determinants are driving the probability to be in a specific state and how relatively large these determinants are, i.e., how important they are from an economic point of view. The estimates are based on the EU SILC data, which are pooled over the years 2007 to 2011. The results in Table 6 show that older workers have a slightly lower probability to be in temporary wage employment and in unemployment and a slightly higher probability to be self-employed. These effects of age are, however, very small relative to the effects of the other covariates on labour market states. Male workers have a higher likelihood to be in all four employment states and a substantially higher likelihood to be unemployed. As we expect, males are by nearly 13 percentage points less likely to be inactive. Educational attainment is a particularly strong predictor of the probability to be in a labour market state. Workers with completed upper secondary education have probabilities to be in permanent wage employment and in professional self-employment that are 23 and 5 percentage points higher than the respective probabilities for workers with less than upper secondary education. The likelihood to be in unemployment or to be inactive is 2.8 and 25 percentage points lower respectively for the former educational category. These relative probabilities have the same signs when we compare workers with tertiary education and workers with less than upper secondary education; the relative magnitudes are, however, augmented

\footnotetext{
${ }^{8}$ In the companion paper we analyse the extent and determinants of informality in Latvian labour market (Lehmann, Razzolini and Zaiceva 2015). LLFS data include information on informal employment based on the lack of a contract for employees; however, this information is only available for the post-crisis years 2011 and 2012 and thus does not allow us to include it as an additional state into the transition matrices in order to study the adjustment throughout the crisis. Informal employment could be in principle also proxied by different definitions using the EU SILC data. Lehmann et al (2015) define informal employees as those for whom their employers do not pay social security contributions. In addition, non-professional employers or self-employed who employ five or fewer workers (including zero workers) are defined as informal self-employed. Also, unpaid family workers are also defined as informal. In this paper, to the purpose of our study we distinguish non-professional self-employed as a separate category.
} 
substantially. It is also striking that the likelihood to be in temporary wage employment is not affected by educational attainment. As expected, workers with tertiary education have a substantially lower likelihood to be in non-professional self-employment.

The marginal effects related to the year dummies are also quite illuminating. They suggest that over the crisis most of the adjustment takes place via the states permanent wage employment and unemployment, while temporary wage employment, non-professional self-employment and inactivity are characterized by very minor adjustments, and professional self-employment seems to be not affected by the crisis. Permanent wage employment reaches a trough in 2010 and unemployment a peak in 2009. In addition, non-professional self-employment moves in the same direction as permanent wage employment, hence they are not substitutes for workers in the Latvian labour market. Finally, only in 2010 do we see a slight increase in the incidence of inactivity. Thus, workers in Latvia do not leave the labour force in larger numbers during the crisis than they do before the crisis. Of course, we should not here that these implied flows do not capture substantial migratory flows out of the country, which constitute an additional adjustment channel.

The estimated transition probabilities between the six states are reported in Table 7, where Panel A shows the estimates for the whole sample and Panels B and C present the transition rates for males and females, respectively. The estimated transition rates for three age cohorts and for three educational groups are presented in the appendix. Inspection of the estimated transition probabilities in panel A of Table 3 produces some very important insights. In all periods the states permanent wage employment, professional and non-professional self-employment as well as inactivity are relatively "stable" since their diagonal entries are always higher than $50 \%$. In other words, only a minority of workers, who are originally in one of these states, flow out of them. In contrast, temporary wage employment is always very volatile since between 2007 and 2011 more than $70 \%$ of workers who are originally in this state exit it for other destinations. In other words, more than two thirds of all workers who at the beginning of the year are in temporary wage employment find themselves in another state at the end of the year. 
The state unemployment has to be thought of differently, since a high percentage in the diagonal entry implies stagnancy and is thus decisively an indication of a poor performance of the labour market (see, e.g., Layard et al. 1991 on this point). The period with the best performance is the pre-crisis year 2007-2008 when more than half of the unemployed flow out of this state within a year. It is, however, noteworthy that a quarter of the unemployed leave the labour force. On our measure the year with the worst performance is 2008 - 2009 when only $45 \%$ leave the unemployment state. The crisis period of $2008-2009$ marks a large increase of the inflows into unemployment. Both for workers in permanent wage employment and in non-professional selfemployment the inflow rates into unemployment triple, while around a quarter of workers originally in temporary wage employment flow every year into unemployment throughout the entire period.

There are some interesting patterns regarding the flows between employment states. The flows from permanent wage employment to the other three employment states are tiny throughout the period. On the other hand, workers originally in temporary wage employment have very large flows into permanent wage employment and small flows into the two types of self-employment. The large transition probabilities into permanent employment are, of course, not surprising since a big chunk of temporary employment is involuntary (see our companion paper, Lehmann et al., 2015) and workers queue in this state to enter permanent jobs. Flows from temporary wage employment to both types of self-employment are small, pointing possibly at the unsuitability of workers who find themselves in temporary wage employment to become self-employed. However, we also see large transition rates from both types of self-employment to permanent wage employment, hinting at self-employment as a potentially unwanted state by a non-negligible number of workers.

Outflow rates out of the labour force are only large for the temporary wage workers and for non-professional self-employment but do not play an important role for the other states. So, on this evidence the only relevant adjustment for the large majority of workers who are in permanent wage employment is at the extensive margin, that is, through flows into unemployment. The converse 
flows, those from unemployment into permanent wage employment hardly vary over the period. This is a little bit surprising as we would expect a fall in these flows during the crisis. The numbers also tell us that by 2010 - 2011 inflows into permanent wage employment are as large as before the crisis apart from the state of inactivity. In general we can say that flows between labour market states roughly return to pre-crisis levels at the end of the observed period.

When we disaggregate by gender (panels B and C) we find much larger increases in labour shedding rates in the crisis period from both permanent wage employment and temporary wage employment for men than for women. Other transitions are quite similar for both sexes apart from the much larger female outflows into inactivity that we observe out of temporary wage employment and unemployment in the years between 2008 and 2010. It is also noteworthy that temporary wage employment is a lot more volatile for women than for men. In the appendix we also present the transitions matrices of three age cohorts as well as by educational attainment. Overall, these matrices demonstrate similar relative labour market experience of the selected demographic groups to that discussed with the $3 \times 3$ matrices in Section 4.1 .

Which factors drive the shown transitions between the six labour market states? To answer this question we performed multinomial logit regressions capturing the probabilities to transit from the respective origin state to the respective destination states. Table 8 reports the average marginal effects of these regressions and presents 6 panels (each panel representing an origin state). We include age, gender, educational attainment and year dummies as covariates in the regressions. When the number of observations in the origin state is large as, for example, in the states permanent employment, unemployment and not-in-the-labour force, the marginal effects can be estimated in a relatively precise fashion since there are enough transitions into any of the other five states. When the number tends to be small like in the other three states, the number in a cell of factors determining the transitions is very limited to allow to provide economically meaningful estimates, which is indicated with the hash sign in the table. 
As panel a of Table 8 shows, older workers are slightly less likely to flow from permanent employment into temporary employment and into unemployment and are slightly more likely to flow into inactivity. However, these effects even if statistically highly significant are economically negligible. Gender and educational attainment are factors that are clearly more important in determining flows from permanent employment. Males have a 1 percentage point higher probability to transit to temporary employment and to professional self-employment, while this higher probability is only $1 / 2$ percentage point when it comes to flows into non-professional selfemployment. Males are 2.5 percentage points more likely to flow into unemployment than their female counterparts, while this effect is reversed by the same amount as far as flows into inactivity are concerned. More education leads to larger flows into professional self-employment and to lower flows into the other four states. The effects are economically meaningful for workers with upper secondary and with tertiary education, but especially large for the latter group.

The marginal effects on the time dummies confirm the notion that the main adjustment of the Latvian labour market during the crisis is via unemployment since only the marginal effects on the time dummies for the EP - U flows are throughout the period positive and large. It is also striking that relative to the pre-crisis period 2007 - 2008 flows into professional self-employment are consistently lower through the rest of the reported period. So, wage workers with permanent contracts find it more difficult to start their own business once the crisis hits the labour market.

The marginal effects of factors driving transitions from temporary wage employment and professional self-employment, which are shown in panels $b$ and c, are poorly estimated for the most part. Older workers in temporary employment are less likely to leave for inactivity, while this age group in professional self-employment has a slightly lower propensity to leave for permanent employment. Male workers in temporary jobs have a far lower probability to move into inactivity than their female counterparts originating from the same state. There is no difference by gender when it comes to withdrawing from professional self-employment into inactivity. Tertiary education, on the other hand, lowers the transitions from professional self-employment to 
permanent wage employment and to inactivity in a substantial fashion, while this factor raises transitions to non-professional self-employment and unemployment in a major way. Finally, the estimated marginal effects do not show any interesting time patterns.

Age shows the same statistical pattern with non-professional self-employment as the origin state as with permanent wage employment: older workers are less likely to flow into temporary employment and unemployment while they have a higher propensity to leave the labour force. A comparison of rows 1 in panel a and panel d shows, however, that these results are economically more meaningful in the case of non-professional self-employment since the marginal effects are much larger. Older workers have a very large proclivity to withdraw from the labour force if they find themselves in non-professional self-employment. The other important result regarding the nonprofessional self-employed considers the marginal effects of the time dummies that drive the flows into unemployment. They are statistically significant and positive for all shown periods and are at least as large as the marginal effects of the time dummies driving the flows between permanent wage employment and unemployment (cf. columns 4 in panel a and d). Thus, for both these states the adjustment takes place at the extensive margin over the crisis, with the effect being larger for non-professional self-employment in the years 2009 - 2011.

Apart from age and gender we find little difference in the determinants of flows from unemployment. Older workers have a slightly lower (higher) proclivity to flow into permanent wage employment (into inactivity). Male workers have a 2.6 percentage points higher likelihood to change to the state of non-professional self-employment and a ten percentage points lower likelihood to enter inactivity from the state of unemployment. Educational attainment, on the other hand has no predictive power regarding the transitions into any state; and this in spite of the fact that the number of workers who find themselves in the origin state unemployment is large. Hence educational attainment does not seem to determine outflows from unemployment into any state; nor do we see any consistent cyclical pattern of transitions from unemployment since the marginal effects of the time dummies are nearly always insignificant. 
Older workers who are in the state of inactivity have a smaller probability to flow into permanent and temporary wage employment and into unemployment, while they are slightly more likely to enter non-professional self-employment. Male workers have a 2.6 percentage points lower likelihood to flow into permanent employment, while workers with secondary and tertiary education have much larger transitions into this state than workers with lesser education. Finally, we also see a clear cyclical pattern of the flows between inactivity and permanent employment and unemployment. As we expect, flows into permanent employment are substantially reduced and flows into unemployment boosted during the crisis years. However, while the decrease in the flows into permanent employment remains roughly constant over the entire period, the increase in the flows into unemployment is halved between 2008 and 2011.

\subsection{Transitions between four aggregated occupational groups}

Interesting transitions can also occur between sectors of the economy and occupations. The longitudinal EU SILC data for Latvia do not contain information on sectors, so we are unable to estimate labour reallocation between sectors. The data set, however, does include occupations, so we can estimate transitions between occupations.

Our focus here is the link between occupational change and upward and downward mobility during the economic recession. ${ }^{9}$ Given the data limitations, we aggregate occupations into four hierarchical groups in order to get economically meaningful results. Occupational group 1 is comprised of legislators, senior officials, managers, professionals and associated professionals. The second group combines clerks, service workers, shop and sales workers. Occupational group 3

\footnotetext{
${ }^{9}$ Workers' selection into occupations has been important issue in the literature of labour markets in transition countries. The study by Sabirianova (2002) looks at upward versus downward occupational mobility in early transition in the Russian labour market. The author finds more downward than upward mobility. Campos and Dabušinkas (2008) look at occupational mobility during early transition in Estonia using the superb Estonian labour force survey covering the years 1989 to 1995 . The authors find evidence that this occupational mobility was substantial: according to their estimates, between 35 and 50\% of all employed Estonian workers changed occupations in half a decade. Moreover, the bulk of these occupational switches happened in the first years, that is, very early in the transition. A more recent paper looks at risk preferences and occupational sorting in the Ukrainian labour market (Dohmen, Kriechel and Skriabikova 2013). They establish that workers who are more prone to take risks sort themselves into occupations that have a larger variance of residual earnings.
} 
refers to skilled agricultural and fishery workers, craft and related trades workers; finally, the last group consists of plant and machine operators and assemblers, and elementary occupations. While this classification is admittedly somewhat arbitrary, it allows us to relatively easily establish occupational upward or downward mobility when estimating movements between the four occupational groups. Movements from a higher number to a lower number represent upward mobility in our case, movements to a higher number - downward mobility, respectively.

Table 9 shows the annual transitions between these occupational groups. Inspection of the table leads us to infer that mobility between these groups is very limited since the lowest percentage of workers remaining in a given occupational group is around 87 percent. Unsurprisingly the movements between the two polar occupational groups (1 and 4) are miniscule apart from the period 2010-2011. There are also very few transitions between groups 2 and 3 in both the upward and downward direction, implying few movements between the lower skills end of white collar occupations and the higher skills end of blue collar occupations.

The off-diagonal elements below the diagonal represent upward occupational mobility while the off-diagonal elements above the diagonal show downward occupational mobility. In the period before the crisis hit the Latvian labour market (2007-2008) we see a lot more upward than downward mobility. Normalized across four occupational groups, 5.2 percent of workers experience upward mobility against 3.3 percent $^{10}$ who find themselves in a lower occupational group at the end of the period relative to its beginning. In the crisis year 2008-2009 we get very limited occupational mobility, upward as well as downward, amounting to roughly 2.5 and 2.2 percent respectively. In 2009-2010 there is actually more downward than upward mobility in the data (2.3 percent upward versus 4.8 percent downward mobility). This is reversed in the last available period of 2010-2011 since we find 5.7 percent of workers moving up and 3.3 percent moving down. The main upshot of these results is that occupational mobility as defined by us is limited in the Latvian labour market during the crisis.

\footnotetext{
${ }^{10}$ The sum of the off-diagonal entries in the first panel of Table 8 is 20.8 below the diagonal and 13.2 above the diagonal; having four occupational groups in the panel we normalize these numbers dividing by 4 .
} 


\section{Wages and mobility during and after the crisis}

This section aims at investigating whether labour mobility across labour market states, occupations and sectors can lead to a more efficient structure of job matches in the economy, resulting in higher productivity and thus higher wages. We start out with a very simple exercise, performing wage regressions and including a dummy for those workers who changed jobs from one year to the next. Using the annual EU SILC longitudinal data over the period 2007 - 2011 we estimate pooled OLS and fixed effects regressions with standard covariates. In some specifications we also include the aggregated occupational groups.

Column 1 of Table 10 reports the results of an OLS regression of the log of real monthly wages on a quadratic in age, gender, educational attainment and year dummies. When we aggregate occupations into four large groups endogeneity issues are attenuated; nevertheless we exclude occupational groups in column 1 to see how robust our estimates are. Consistent with earlier studies for Latvia, wages are rising in age at a decreasing rate, and there is a quite large gender wage gap as well as large returns to education. These results hold when we include occupational groups in column 2, with the gender gap actually increasing to roughly 40 percent. Adding a dummy for annual job-to-job moves again does not change the coefficient estimates (column 3). The crucial result here is that the mobility dummy is negative and large, implying that those who change jobs experience a wage penalty on average. Table 11 supplements this analysis by presenting the yearby-year coefficients on the job change dummy. As can be seen from this table, wage penalty for those who change jobs is the lowest in 2010 and the highest in the following year.

These OLS results are biased if unobservable characteristics influence significantly both wages and covariates and are omitted from the regressions. The fixed effects results in column 4 of Table 10 account for unobserved time-invariant workers' characteristics and show no wage penalty caused by a job change. Hence a wage penalty seems to arise because of adverse selection. In other words, according to these results workers who change jobs have on average worse unobserved characteristics than those who are able to retain their jobs. On the basis of these results worker 
mobility does not seem to lead to a more productive job structure in the Latvian economy during the crisis.

To probe somewhat deeper into the issue of job change and wages we create three mutually exclusive dummy variables: a variable for upward mobility, that is for movements from a higher numbered occupational group to a lower numbered occupational group, a variable for downward mobility, which describes the opposite movement and a variable when a job change entails no movements between occupational groups. We then interact these mobility dummies with the job change dummy in our wage regressions. Table 12 shows the coefficients of these interaction terms. In column 2 we do not control for occupational group while in column 3 occupational group is an additional control variable. By introducing the interaction term and controlling for occupational group we eliminate some of the bias due to unobserved characteristics like motivation or ability. When we do not control for occupational group the coefficients of the interaction terms show small differences across the three mobility groups that are not statistically significant. Once we control for occupational group we get statistically significant differences as far as upward and downward mobility is concerned. Those workers who are upwardly mobile do not experience a wage penalty when they change jobs, while those who move down in the occupational ladder are confronted with a $24 \%$ wage penalty. In the light of the standard errors the difference between the zero and the $24 \%$ penalty is statistically significant, while the difference in the penalties of those who move down and those who stay in the same occupational group albeit numerically large is not statistically significant.

Why do we not observe a wage premium for those who are occupationally upwardly mobile? Having no information on where these workers come from and in which firms they land their new jobs we can only speculate. A negative impact of the business cycle may definitely play a role. Selective out-migration may be another reason when those with particularly high likelihood of improved productivity move out. Third, and maybe most importantly, as long as within firms there exists an upward sloping wage profile with respect to tenure (for example, because of a seniority 
pay system or because of the accumulation of firm specific human capital), workers will lose their positions in the previous firms' wage structure when they change jobs. Starting a new job, they will have lost firm specific human capital and all the tenure accumulated with the previous employer (see Lehmann and Wadsworth 2000 on this). Only in the case of strong upward occupational mobility, which is the case when workers move from a higher to a lower numbered occupational group, will workers in their new job not face a lower wage than in their previous employment. Interpreting the absence of a wage penalty for workers who show strong upward occupational mobility in this way allows us to infer that part of the observed labour reallocation may result in improved productivity in the Latvian labour market during the crisis. However, as we have noted in the discussion of the transitions between occupational groups of Table 9, for most years we have more upward than downward mobility and, on the other hand, the vast majority of job changers remain in the same occupational group throughout the period. Hence according to this evidence overall job reallocation does not lead to an increase in labour productivity and higher wages during and shortly after the crisis.

\section{Conclusions}

In this paper we analyse labour market adjustment to a large macroeconomic shock by estimating transitions for different sets of labour market states and the associated impact of job mobility on wages in Latvia, a country that faced one of the largest recessions in Europe and a subsequent remarkable recovery. On the basis of the estimated $3 \times 3$ matrices we can state that it is the period 2008 to 2009 when the crisis has its major impact on the Latvian labour market. In this period flows from employment to unemployment shoot up dramatically for the whole sample but also for all demographic categories. This large increase should be interpreted as a result of major labour shedding with the onset of the crisis. We also show that males, young workers and workers with less than secondary education have the largest inflow rates into unemployment. Outflow rates, on 
the other hand, fall only slightly in the years after 2008 and thus the duration of unemployment increases during the crisis. A large rise of the inflow rate into unemployment in combination with a increased duration of unemployment results in a substantially larger incidence of long-term unemployment, a result consistent with documented increase in long-term unemployment in Latvia in Lehmann et al. (2015). While in the last observed period of 2010 to 2011 the outflow rates from unemployment recover somewhat and the inflow rates are reduced, these improvements in the flow patterns are not large enough to decrease the incidence of long-term unemployment notably. Thus, while overall unemployment decreases, long-term unemployment becomes important because of its persistence. From a policy perspective, policies are required that increase outflow rates from unemployment, and in particular from long-term unemployment. Measures that increase the search effectiveness of the unemployed and/or training measures that enhance the productivity of the problem groups among the unemployed, as well as subsidies to hire the long-term unemployed are all potential tools that can result in a boost of outflows from unemployment.

Our results also show that the strongest determinant of transitions from employment to unemployment is by far sector affiliation. We also find that Latvian workers have a better labour market experience than their non-Latvian counterparts insofar as they have lower job loss rates and higher job accession rates from unemployment. Residing in metropolitan Riga, on the other hand, produces only slight advantages.

The estimated results for six labour market states show some very clear patterns. Male workers have a roughly 2 percentage points higher likelihood to be in any of the four employment states, and a whopping 6 percentage points higher probability to be unemployed, while they are substantially less prone to be inactive than their female counterparts. What mainly drives the probability to be in any of the states apart from temporary employment is educational attainment. Better educated workers have a far higher propensity to be in permanent wage employment and professional self-employment; also they by a wide margin are less likely to be in unemployment and inactivity. The marginal effects on the time dummies show clearly that labour market 
adjustment during the crisis predominantly takes place via large reductions in permanent wage employment and large increases in unemployment, while the other four states seem hardly affected.

The $6 x 6$ transition probability matrices also suggest that permanent wage employment, professional and non-professional self-employment are relatively stable states, while temporary wage employment is very volatile, since annual outflow rates out of this state are more than 70 percent throughout the period. In addition, we find that there are large flows from temporary wage and the two types of self-employment to permanent wage employment hinting at the fact that these states are involuntary choice by many workers. The evidence also shows that the only substantial flows out of permanent wage employment are into unemployment confirming that labour market adjustment to the crisis occurs at the extensive margin in Latvia.

When slicing the data by gender we find substantially larger EU flows for men than for women. Multinomial logit regressions demonstrate that gender and above all educational attainment drive the transitions. For example, workers with tertiary education are 9 percentage points less likely to flow into unemployment and 3 percentage points more likely to flow into professional selfemployment than workers with only primary education or less. The regressions also confirm that permanent wage employment and unemployment are the main states where adjustment occurs in the Latvian labour market.

Our analysis of upward and downward occupational mobility aggregating occupations into four groups shows that only a small percentage of workers leave their occupational group throughout the period, and that upward mobility is slightly larger than downward mobility in most of the years. Wage regressions that include a dummy for job change and interaction terms of this dummy with occupational mobility indicate that job mobility does not lead to an overall increase of labour productivity in the Latvian labour market during and immediately after the crisis. This result is not that surprising given the period of the Great Recession when many workers change jobs involuntarily. 
One major caveat of this analysis that needs to be kept in mind regards migration flows. Out-migration may relieve labour market of excess labour if unemployed individuals emigrate and serve as an additional important adjustment mechanism during the crisis. Bertoli et al (2013) provide evidence of "migration diversion" during the crisis into Germany, a country which performed exceptionally well, the result confirmed also by Elsner and Zimmermann (2016) who find increased migration to Germany both from the new EU member states and from Southern European countries. Hazans and Philips (2010), Hazans (2013), Elsner (2013a,b) demonstrate that emigration from the Baltic countries has contributed to a decline in unemployment as well as wage growth before the crisis particularly for groups affected by it (young, men, lower skilled), and has also improved bargaining power of lower skilled employees and contributed to skill shortages in certain sectors. Out-migration has also contributed to the improvements of the labour market position of ethnic minorities (Hazans and Philips, 2010). The data at our disposal does not allow us to fully evaluate the effect of out-migration as an adjustment tool and further research is needed, including the impact of return migration as well as the impact of emigration on the demography and welfare in countries hit severely by the crisis.

Our work nevertheless provides important insights for policy makers in countries affected by severe recessions. First, contingent employment and self-employment do not appear as important buffers in the recession; it is nearly exclusively unemployment that absorbs the shocks during the crisis. Second, we observe large inflows into unemployment during the crisis and only slowly recovering outflow rates from unemployment immediately after the crisis. These flow patterns cause a sustained build-up of long-term unemployment. If there is state dependence this built-up stock of long-term unemployed is hard to reduce even if the economy picks up again (see, e.g., Layard, Nickell and Jackman 1991). Third, our analysis identifies two main problem groups among the workforce. It is male workers who are more affected by labour shedding but also by lower outflow rates from unemployment into permanent wage employment. Importantly, it is mainly less educated workers who perform badly along many dimensions. A combination of active labour 
market policies such as training and job search measures and of social policies might attenuate the difficult situation of these workers. 


\section{References}

Bellmann, L., Estrin, S., Lehmann, H. and Wadsworth, J. 1995. The Eastern German Labour Market in Transition: Gross Flow Estimates from Panel Data. Journal of Comparative Economics, vol.20, n.1, 137-170.

Bertoli, S., H. Brücker and J. Fernández-Huertas Moraga (2013). The European Crisis and Migration to Germany: Expectations and the Diversion of Migration Flows. IZA Discussion Paper No. 7170.

Campos, N.F. and Dabušinkas, A. 2008. So Many Rocket Scientists, So Few Marketing Clerks: Estimating the Effects of Market Reform on Occupational Mobility. IZA Discussion Paper No. 3886. Institute for the Study of Labor, IZA, Bonn.

Clark, K. and Summers, L. 1979. Labor Market Dynamics and Unemployment: a Reconsideration. Brookings Papers on Economic Activity, Spring 13 - 60 .

Dohmen, T., Kriechel, B. and Skriabikova, O. 2013. Risk Attitudes and Occupational Choice, ROA, Maastricht University, mimeo.

Elsner, B. (2013a). Emigration and Wages: The EU Enlargement Experiment. Journal of International Economics, 2013, 91(1), 154-163.

Elsner, B. (2013b). Does Emigration Benefit the Stayers? Evidence from EU Enlargement. Journal of Population Economics, 2013, 26 (2), 531-553.

Elsner, B. and K. F. Zimmermann (2016). "10 Years After: EU Enlargement, Closed Borders, and Migration to Germany”. Forthcoming in: Martin Kahanec and Klaus F. Zimmermann (eds), Labor Migration, EU Enlargement, and the Great Recession. Springer: Berlin et al.

Fadejeva, L. and Krasnopjorovs, O. 2015. Labour Market Adjustment during 2008 - 2013 in Latvia: Firm Level Evidence, Latvijas Banka, Working Paper No. 2/2015.

Hazans, M. (2016). "Migration Experience of the Baltic Countries in the Context of Economic Crisis", Forthcoming in: Martin Kahanec and Klaus F. Zimmermann (eds), Labor Migration, EU Enlargement, and the Great Recession. Springer: Berlin et al. 
Hazans, M. (2013). "Emigration from Latvia: Recent trends and economic impact", in OECD, Coping with Emigration in Baltic and East European Countries, OECD Publishing, Ch. 4, 65-110.

Hazans, M. (2011a). "Labor market integration of ethnic minorities in Latvia", in Martin Kahanec and Klaus F. Zimmermann (eds), Ethnic diversity in European labor markets: Challenges and solutions, Cheltenham, UK - Northampton, MA, USA: Edward Elgar, 163-197

Hazans, M. (2011b). "Informal Workers across Europe: Evidence from 30 Countries", IZA Discussion Paper No. 5871

Hazans, M. and K. Philips (2010). The Post-Enlargement Migration Experience in the Baltic Labor Markets. In: M. Kahanec and K. F. Zimmermann (eds), EU Labor Markets After PostEnlargement Migration, Berlin - Heidelberg: Springer, 255-304.

Ivlevs, A., Piacentini, M. and Upward, R. (2009) The effects of the economic downturn on migration from the New EU Member States to the United Kingdom. In: COMPAS Annual Conference 2009: New Times? Economic Crisis, Geo-Political Transformation and the Emergent Migration Order, Centre on Migration, Policy and Society, University of Oxford, UK, September 2009.

La Porta, R. and Shleifer, A. 2008. The Unofficial Economy and Economic Development. Brookings Papers on Economic Activity, Fall: 275 - 352.

Layard, R., Nikell, S. and Jackman, R. 1991. Unemployment . Macroeconomic Performance and the Labour Market, Oxford University Press.

Lehmann, H. and Pignatti, N. 2007. Informal Employment and Labor Market Segmentation in Transition Economies: Evidence from Ukraine. IZA Discussion Paper No. 3269. Institute for the Study of Labor, IZA, Bonn.

Lehmann, H. and Wadsworth, J. 2000. Tenures that Shook the World: Worker Turnover in Russia, Poland and Britain. Journal of Comparative Economics, vol. 28, no. 4, 639-664.

Lehmann, H., T. Razzolini and A. Zaiceva (2015). Labour market trends in Latvia over the Great Recession: Analysing key labour market aggregates and wages. IZA Policy Paper, forthcoming. 
Rutkowski, J. (2007). From the Shortage of Jobs to the Shortage of Skilled Workers: Labor Markets in the EU New Member States, IZA Discussion Paper No. 3202.

Sabirianova, K. 2002. The Great Human Capital Reallocation: A Study of Occupational Mobility in Transitional Russia. Journal of Comparative Economics, vol. 30, no. 1, 191-217.

Zaiceva, A. and K. F. Zimmermann (2016). Returning Home at Times of Trouble? Return Migration of EU Enlargement Migrants during the Crisis. Forthcoming in: Martin Kahanec and Klaus F. Zimmermann (eds), Labor Migration, EU Enlargement, and the Great Recession. Springer: Berlin et al. 
Table 1. Annual labour market transitions: three states - 2007 to 2011

\begin{tabular}{|c|c|c|c|c|c|c|c|c|c|}
\hline & $\mathrm{EE}$ & EU & EN & UE & UU & UN & $\mathrm{NE}$ & $\mathrm{NU}$ & $\mathrm{NN}$ \\
\hline & \multicolumn{9}{|c|}{2007 to 2008} \\
\hline Total & 0.879 & 0.053 & 0.068 & 0.308 & 0.449 & 0.243 & 0.162 & 0.029 & 0.809 \\
\hline Males & 0.862 & 0.074 & 0.064 & 0.328 & 0.484 & 0.188 & 0.137 & 0.038 & 0.825 \\
\hline Females & 0.897 & 0.032 & 0.071 & 0.279 & 0.395 & 0.326 & 0.178 & 0.023 & 0.799 \\
\hline Age 16-24 & 0.754 & 0.076 & 0.169 & 0.455 & 0.273 & 0.273 & 0.139 & 0.025 & 0.836 \\
\hline Age 25-54 & 0.904 & 0.056 & 0.041 & 0.292 & 0.514 & 0.194 & 0.297 & 0.074 & 0.628 \\
\hline Age 55-64 & 0.833 & 0.022 & 0.144 & 0.300 & 0.350 & 0.350 & 0.080 & 0.000 & 0.920 \\
\hline Primary & 0.781 & 0.086 & 0.132 & 0.344 & 0.344 & 0.313 & 0.087 & 0.017 & 0.896 \\
\hline Upper sec. & 0.889 & 0.051 & 0.060 & 0.296 & 0.463 & 0.241 & 0.185 & 0.032 & 0.784 \\
\hline \multirow[t]{2}{*}{ Tertiary } & 0.949 & 0.014 & 0.037 & 0.400 & 0.400 & 0.200 & 0.308 & 0.000 & 0.692 \\
\hline & \multicolumn{9}{|c|}{2008 to 2009} \\
\hline Total & 0.809 & 0.137 & 0.054 & 0.298 & 0.551 & 0.151 & 0.144 & 0.123 & 0.733 \\
\hline Males & 0.773 & 0.178 & 0.049 & 0.249 & 0.633 & 0.118 & 0.117 & 0.120 & 0.763 \\
\hline Females & 0.843 & 0.099 & 0.058 & 0.371 & 0.431 & 0.198 & 0.159 & 0.125 & 0.716 \\
\hline Age 16-24 & 0.686 & 0.227 & 0.087 & 0.308 & 0.462 & 0.231 & 0.103 & 0.139 & 0.757 \\
\hline Age 25-54 & 0.842 & 0.134 & 0.024 & 0.308 & 0.579 & 0.113 & 0.237 & 0.190 & 0.573 \\
\hline Age 55-64 & 0.719 & 0.103 & 0.178 & 0.282 & 0.410 & 0.308 & 0.090 & 0.031 & 0.879 \\
\hline Primary & 0.643 & 0.254 & 0.104 & 0.237 & 0.588 & 0.175 & 0.081 & 0.099 & 0.820 \\
\hline Upper sec. & 0.815 & 0.137 & 0.048 & 0.320 & 0.541 & 0.140 & 0.156 & 0.133 & 0.711 \\
\hline \multirow[t]{2}{*}{ Tertiary } & 0.893 & 0.069 & 0.038 & 0.345 & 0.517 & 0.138 & 0.298 & 0.114 & 0.588 \\
\hline & \multicolumn{9}{|c|}{2009 to 2010} \\
\hline Total & 0.825 & 0.094 & 0.081 & 0.289 & 0.523 & 0.188 & 0.106 & 0.079 & 0.814 \\
\hline Males & 0.835 & 0.110 & 0.055 & 0.301 & 0.557 & 0.142 & 0.092 & 0.079 & 0.829 \\
\hline Females & 0.816 & 0.082 & 0.102 & 0.271 & 0.472 & 0.257 & 0.116 & 0.080 & 0.804 \\
\hline Age 16-24 & 0.716 & 0.164 & 0.121 & 0.239 & 0.441 & 0.319 & 0.118 & 0.092 & 0.790 \\
\hline Age $25-54$ & 0.861 & 0.092 & 0.047 & 0.336 & 0.572 & 0.092 & 0.187 & 0.145 & 0.668 \\
\hline Age 55-64 & 0.702 & 0.057 & 0.242 & 0.147 & 0.382 & 0.471 & 0.037 & 0.014 & 0.950 \\
\hline Primary & 0.687 & 0.180 & 0.133 & 0.249 & 0.538 & 0.213 & 0.060 & 0.072 & 0.867 \\
\hline Upper sec. & 0.827 & 0.099 & 0.075 & 0.287 & 0.551 & 0.162 & 0.109 & 0.072 & 0.819 \\
\hline \multirow[t]{2}{*}{ Tertiary } & 0.876 & 0.051 & 0.072 & 0.378 & 0.396 & 0.225 & 0.242 & 0.068 & 0.689 \\
\hline & \multicolumn{9}{|c|}{2010 to 2011} \\
\hline Total & 0.883 & 0.083 & 0.034 & 0.359 & 0.492 & 0.149 & 0.106 & 0.081 & 0.813 \\
\hline Males & 0.878 & 0.099 & 0.022 & 0.355 & 0.534 & 0.111 & 0.092 & 0.093 & 0.815 \\
\hline Females & 0.887 & 0.069 & 0.045 & 0.364 & 0.439 & 0.197 & 0.116 & 0.073 & 0.811 \\
\hline Age 16-24 & 0.792 & 0.137 & 0.071 & 0.336 & 0.504 & 0.160 & 0.101 & 0.074 & 0.825 \\
\hline Age $25-54$ & 0.894 & 0.085 & 0.021 & 0.394 & 0.490 & 0.116 & 0.185 & 0.160 & 0.655 \\
\hline Age 55-64 & 0.852 & 0.063 & 0.086 & 0.221 & 0.497 & 0.282 & 0.046 & 0.035 & 0.919 \\
\hline Primary & 0.776 & 0.173 & 0.051 & 0.286 & 0.559 & 0.155 & 0.051 & 0.054 & 0.896 \\
\hline Upper sec. & 0.878 & 0.088 & 0.034 & 0.352 & 0.490 & 0.158 & 0.114 & 0.084 & 0.803 \\
\hline Tertiary & 0.929 & 0.042 & 0.029 & 0.510 & 0.392 & 0.098 & 0.206 & 0.085 & 0.709 \\
\hline
\end{tabular}

Source: EU SILC longitudinal data set. 
Table 2. Transition probability matrices using the Latvian Labour Force Survey

\begin{tabular}{|c|c|c|c|c|c|c|c|c|c|}
\hline & $\mathrm{EE}$ & EU & $\mathrm{EN}$ & UE & $\overline{\mathrm{UU}}$ & UN & $\mathrm{NE}$ & $\mathrm{NU}$ & $\mathrm{NN}$ \\
\hline & \multicolumn{9}{|c|}{2007 to 2008} \\
\hline Total & 0.906 & 0.036 & 0.057 & 0.538 & 0.205 & 0.255 & 0.174 & 0.048 & 0.776 \\
\hline Males & 0.912 & 0.042 & 0.045 & 0.547 & 0.261 & 0.190 & 0.170 & 0.053 & 0.775 \\
\hline Females & 0.901 & 0.031 & 0.067 & 0.528 & 0.144 & 0.327 & 0.177 & 0.045 & 0.777 \\
\hline Riga & 0.915 & 0.032 & 0.051 & 0.653 & 0.107 & 0.238 & 0.192 & 0.052 & 0.755 \\
\hline \multirow[t]{2}{*}{ Not Riga } & 0.902 & 0.038 & 0.059 & 0.495 & 0.242 & 0.262 & 0.167 & 0.047 & 0.784 \\
\hline & \multicolumn{9}{|c|}{2008 to 2009} \\
\hline Total & 0.841 & 0.095 & 0.063 & 0.283 & 0.467 & 0.249 & 0.112 & 0.088 & 0.798 \\
\hline Males & 0.815 & 0.126 & 0.058 & 0.286 & 0.497 & 0.216 & 0.096 & 0.090 & 0.812 \\
\hline Females & 0.866 & 0.066 & 0.067 & 0.279 & 0.430 & 0.290 & 0.124 & 0.086 & 0.788 \\
\hline Riga & 0.841 & 0.093 & 0.064 & 0.284 & 0.426 & 0.289 & 0.106 & 0.089 & 0.803 \\
\hline \multirow[t]{2}{*}{ Not Riga } & 0.841 & 0.095 & 0.062 & 0.282 & 0.485 & 0.231 & 0.115 & 0.088 & 0.796 \\
\hline & \multicolumn{9}{|c|}{2009 to 2010} \\
\hline Total & 0.865 & 0.070 & 0.063 & 0.325 & 0.458 & 0.216 & 0.121 & 0.108 & 0.769 \\
\hline Males & 0.854 & 0.087 & 0.058 & 0.322 & 0.495 & 0.182 & 0.125 & 0.124 & 0.749 \\
\hline Females & 0.873 & 0.056 & 0.070 & 0.330 & 0.401 & 0.269 & 0.118 & 0.096 & 0.785 \\
\hline Riga & 0.870 & 0.072 & 0.057 & 0.347 & 0.468 & 0.183 & 0.102 & 0.126 & 0.771 \\
\hline \multirow[t]{2}{*}{ Not Riga } & 0.862 & 0.069 & 0.068 & 0.314 & 0.453 & 0.231 & 0.128 & 0.102 & 0.769 \\
\hline & \multicolumn{9}{|c|}{2010 to 2011} \\
\hline Total & 0.910 & 0.046 & 0.043 & 0.384 & 0.414 & 0.201 & 0.107 & 0.089 & 0.802 \\
\hline Males & 0.909 & 0.051 & 0.038 & 0.401 & 0.443 & 0.155 & 0.108 & 0.092 & 0.798 \\
\hline Females & 0.911 & 0.041 & 0.047 & 0.363 & 0.380 & 0.256 & 0.106 & 0.086 & 0.806 \\
\hline Riga & 0.924 & 0.039 & 0.036 & 0.391 & 0.412 & 0.196 & 0.111 & 0.095 & 0.793 \\
\hline Not Riga & 0.903 & 0.049 & 0.046 & 0.380 & 0.416 & 0.203 & 0.106 & 0.086 & 0.807 \\
\hline \multicolumn{10}{|c|}{2011 to 2012} \\
\hline Total & 0.913 & 0.046 & 0.039 & 0.346 & 0.451 & 0.202 & 0.128 & 0.103 & 0.768 \\
\hline Males & 0.912 & 0.053 & 0.034 & 0.350 & 0.479 & 0.170 & 0.141 & 0.105 & 0.753 \\
\hline Females & 0.914 & 0.041 & 0.045 & 0.339 & 0.410 & 0.249 & 0.118 & 0.102 & 0.779 \\
\hline Riga & 0.939 & 0.032 & 0.028 & 0.388 & 0.424 & 0.188 & 0.132 & 0.099 & 0.768 \\
\hline Not Riga & 0.898 & 0.055 & 0.046 & 0.322 & 0.466 & 0.211 & 0.126 & 0.105 & 0.768 \\
\hline
\end{tabular}


Table 3. Determinants of transitions from employment: MNL regressions, marginal effects

\begin{tabular}{|c|c|c|c|}
\hline & $E-E$ & $E-U$ & $\mathrm{E}-\mathrm{N}$ \\
\hline \multicolumn{4}{|l|}{ Demographics } \\
\hline \multirow[t]{2}{*}{ Male } & 0.0003 & $0.0052 *$ & $-0.0055^{* *}$ \\
\hline & $(0.003)$ & $(0.003)$ & $(0.002)$ \\
\hline \multirow[t]{2}{*}{ Riga } & $0.0092 * * *$ & $-0.0052 *$ & $-0.0040 *$ \\
\hline & $(0.003)$ & $(0.002)$ & $(0.002)$ \\
\hline \multirow[t]{2}{*}{$25-54$} & $0.0319 * * *$ & $-0.0151 * * *$ & $-0.0167 * * *$ \\
\hline & $(0.005)$ & $(0.004)$ & $(0.004)$ \\
\hline \multirow[t]{2}{*}{$55-64$} & $0.0117 *$ & $-0.0342 * * *$ & $0.0225 * * *$ \\
\hline & $(0.006)$ & $(0.005)$ & $(0.004)$ \\
\hline \multirow[t]{2}{*}{ Latvian } & $0.0139 * * *$ & $-0.0113 * * *$ & -0.0026 \\
\hline & $(0.003)$ & $(0.002)$ & $(0.002)$ \\
\hline \multirow[t]{2}{*}{ Upper secondary } & $0.0315^{* * *}$ & $-0.0162 * * *$ & $-0.0152 * * *$ \\
\hline & $(0.004)$ & $(0.003)$ & $(0.002)$ \\
\hline \multirow[t]{2}{*}{ Tertiary } & $0.0583 * * *$ & $-0.0353 * * *$ & $-0.0230 * * *$ \\
\hline & $(0.006)$ & $(0.005)$ & $(0.004)$ \\
\hline \multicolumn{4}{|l|}{ Sectors } \\
\hline \multirow[t]{2}{*}{ Mining and manuf. } & $-0.0318 * * *$ & $0.0260 * * *$ & 0.0058 \\
\hline & $(0.006)$ & $(0.004)$ & $(0.004)$ \\
\hline \multirow[t]{2}{*}{ Construction } & $-0.0730 * * *$ & $0.0685 * * *$ & 0.0045 \\
\hline & $(0.008)$ & $(0.007)$ & $(0.005)$ \\
\hline \multirow[t]{2}{*}{ Trade } & $-0.0315 * * *$ & $0.0310 * * *$ & 0.0004 \\
\hline & $(0.007)$ & $(0.005)$ & $(0.004)$ \\
\hline \multirow[t]{2}{*}{ Accom.\&food service } & $-0.0338 * * *$ & $0.0259 * * *$ & 0.0078 \\
\hline & $(0.011)$ & $(0.008)$ & $(0.007)$ \\
\hline \multirow[t]{2}{*}{ Transportation } & -0.0013 & $0.0127 * *$ & $-0.0114 * *$ \\
\hline & $(0.006)$ & $(0.005)$ & $(0.004)$ \\
\hline \multirow[t]{2}{*}{ Finance\&insurance } & -0.0242 & 0.0078 & 0.0164 \\
\hline & $(0.015)$ & $(0.0105)$ & $(0.012)$ \\
\hline \multirow[t]{2}{*}{ Real estate } & $-0.0634 * * *$ & $0.0437 * * *$ & $0.0197 * * *$ \\
\hline & $(0.009)$ & $(0.007)$ & $(0.006)$ \\
\hline \multirow[t]{2}{*}{ Public adm.\&defence } & $-0.0133^{*}$ & 0.0023 & $0.0109 *$ \\
\hline & $(0.007)$ & $(0.005)$ & $(0.006)$ \\
\hline \multirow[t]{2}{*}{ Education } & -0.0037 & -0.0001 & 0.0037 \\
\hline & $(0.007)$ & $(0.004)$ & $(0.005)$ \\
\hline Health\&social work & 0.0099 & -0.0070 & -0.0028 \\
\hline & $(0.007)$ & $(0.004)$ & $(0.005)$ \\
\hline Arts\&otherservices & $-0.0181 * *$ & $0.0198 * * *$ & -0.0017 \\
\hline & $(0.008)$ & $(0.006)$ & $(0.005)$ \\
\hline Occupations & & & \\
\hline Professionals & $-0.0108 *$ & 0.0062 & 0.0046 \\
\hline & $(0.006)$ & $(0.005)$ & $(0.004)$ \\
\hline Technicians & $-0.0208 * * *$ & $0.0165^{* * *}$ & 0.0043 \\
\hline & $(0.006)$ & $(0.005)$ & $(0.004)$ \\
\hline Clerks & $-0.0275 * * *$ & 0.0073 & $0.0201 * * *$ \\
\hline & $(0.008)$ & $(0.006)$ & $(0.005)$ \\
\hline Service workers & $-0.0417 * * *$ & $0.0204 * * *$ & $0.0212 * * *$ \\
\hline & $(0.006)$ & $(0.005)$ & $(0.004)$ \\
\hline Skilled agr.fish.workers & -0.0079 & 0.0071 & 0.0008 \\
\hline & $(0.009)$ & $(0.008)$ & $(0.005)$ \\
\hline Craft workers & $-0.0343 * * *$ & $0.0197 * * *$ & $0.0145^{* * *}$ \\
\hline & $(0.006)$ & $(0.004)$ & $(0.004)$ \\
\hline Operators\&assemblers & $-0.0221 * * *$ & $0.0119 * *$ & $0.0101 * *$ \\
\hline & $(0.006)$ & $(0.005)$ & $(0.004)$ \\
\hline Elem. occupations & $-0.0567 * * *$ & $0.0351 * * *$ & $0.0215 * * *$ \\
\hline & $(0.006)$ & $(0.005)$ & $(0.004)$ \\
\hline future attriters ${ }^{\S}$ & $0.0164 * * *$ & $-0.0158 * * *$ & -0.0006 \\
\hline & $(0.006)$ & $(0.004)$ & $(0.003)$ \\
\hline
\end{tabular}


Source: Latvian Labour Force Survey, years 2007 - 2012.* significant at the 10 percent level, ** significant at the 5 percent level, $* * *$ significant at the 1 percent level. ${ }^{\S}$ The coefficients on dummies of future attriters are taken from separate regressions.

Table 4. Determinants of transitions from unemployment: MNL regressions, marginal effects

\begin{tabular}{lccc}
\hline \hline & $\mathrm{U}-\mathrm{E}$ & $\mathrm{U}-\mathrm{U}$ & $\mathrm{U}-\mathrm{N}$ \\
\cline { 2 - 4 } Demographics & & & \\
Male & 0.0241 & $0.0729 * * *$ & $-0.0971 * * *$ \\
& $(0.015)$ & $(0.015)$ & $(0.012)$ \\
Riga & $0.0420 * * *$ & -0.0224 & -0.0196 \\
& $(0.015)$ & $(0.016)$ & $(0.013)$ \\
$25-54$ & $0.0361 *$ & $0.0747 * * *$ & $-0.1109 * * *$ \\
& $(0.020)$ & $(0.021)$ & $(0.015)$ \\
$55-64$ & $-0.0593 * *$ & -0.01361 & $0.0729 * * *$ \\
& $(0.028)$ & $(0.028)$ & $(0.019)$ \\
Latvian & $0.0737 * * *$ & $-0.0691 * * *$ & -0.0046 \\
& $(0.014)$ & $(0.015)$ & $(0.012)$ \\
Upper secondary & $0.1052 * * *$ & -0.0267 & $-0.0785 * * *$ \\
& $(0.019)$ & $(0.019)$ & $(0.014)$ \\
Tertiary & $0.1614 * * *$ & $-0.0950 * * *$ & $-0.0663 * * *$ \\
& $(0.027)$ & $(0.029)$ & $(0.023)$ \\
future attriters ${ }^{\S}$ & -0.0096 & -0.0376 & $0.0472 * *$ \\
& $(0.025)$ & $(0.026)$ & $(0.020)$ \\
\hline
\end{tabular}

Source: Latvian Labour Force Survey, years $2007-2012 .{ }^{*}$ significant at the 10 percent level, ** significant at the 5 percent level, *** significant at the 1 percent level. ${ }^{\S}$ The coefficients on dummies of future attriters are taken from separate regressions.

Table 5. Determinants of transitions from inactivity: MNL regressions, marginal effects

\begin{tabular}{|c|c|c|c|}
\hline & $\overline{N-E}$ & $\overline{\mathrm{N}-\mathrm{U}}$ & $\mathrm{N}-\mathrm{N}$ \\
\hline \multicolumn{4}{|l|}{ Demographics } \\
\hline Male & $\begin{array}{c}0.0224 * * * \\
(0.005)\end{array}$ & $\begin{array}{c}0.0226 * * * \\
(0.004)\end{array}$ & $\begin{array}{c}-0.0451^{* *} \\
(0.006)\end{array}$ \\
\hline Riga & $\begin{array}{l}-0.0094 \\
(0.006)\end{array}$ & $\begin{array}{c}-0.00003 \\
(0.005)\end{array}$ & $\begin{array}{l}0.0095 \\
(0.007)\end{array}$ \\
\hline $25-54$ & $\begin{array}{c}0.0842 * * * \\
(0.006)\end{array}$ & $\begin{array}{c}0.0401 * * * \\
(0.005)\end{array}$ & $\begin{array}{c}-0.1243 * * * \\
(0.007)\end{array}$ \\
\hline $55-64$ & $\begin{array}{c}-0.0338 * * * \\
(0.007)\end{array}$ & $\begin{array}{c}-0.0793 * * * \\
(0.007)\end{array}$ & $\begin{array}{c}0.1132 * * * \\
(0.009)\end{array}$ \\
\hline Latvian & $\begin{array}{c}0.0217 * * * \\
(0.005)\end{array}$ & $\begin{array}{c}-0.0195^{* * *} \\
(0.004)\end{array}$ & $\begin{array}{l}-0.0021 \\
(0.006)\end{array}$ \\
\hline Upper secondary & $\begin{array}{c}0.0928 * * * \\
(0.006)\end{array}$ & $\begin{array}{c}0.0605 * * * \\
(0.005)\end{array}$ & $\begin{array}{c}-0.1534 * * * \\
(0.007)\end{array}$ \\
\hline Tertiary & $\begin{array}{c}0.1780 * * * \\
(0.009)\end{array}$ & $\begin{array}{c}0.0846 * * * \\
(0.008)\end{array}$ & $\begin{array}{c}-0.2627 * * * \\
(0.011)\end{array}$ \\
\hline future attriters ${ }^{\S}$ & $\begin{array}{c}0.0342 * * * \\
(0.008)\end{array}$ & $\begin{array}{c}-0.0450 * * * \\
(0.008)\end{array}$ & $\begin{array}{l}0.0107 \\
(0.011)\end{array}$ \\
\hline
\end{tabular}

Source: Latvian Labour Force Survey, years 2007 - 2012. * significant at the 10 percent level, ** significant at the 5 percent level, $* * *$ significant at the 1 percent level. ${ }^{\S}$ The coefficients on dummies of future attriters are taken from separate regressions. 
Table 6. Determinants of probability of being in labour market states - Multinomial logit, Marginal effects

\begin{tabular}{lcccccc}
\hline \hline Age & $\begin{array}{c}\text { Permanent } \\
\text { employee }\end{array}$ & $\begin{array}{c}\text { Temporary } \\
\text { employee }\end{array}$ & $\begin{array}{c}\text { Self- } \\
\text { employed } \\
\text { professional }\end{array}$ & $\begin{array}{c}\text { Self-employed } \\
\text { Non- } \\
\text { professional }\end{array}$ & Unemployed & Inactive \\
\cline { 2 - 6 } Male & 0.00004 & $-0.0003 * * *$ & $0.0004 * * *$ & $0.0007 * * *$ & $-0.0007 * * *$ & -0.0002 \\
Upper & $(0.0001)$ & $(0.00007)$ & $(0.00007)$ & $(0.00007)$ & $(0.0001)$ & $(0.0002)$ \\
secondary & $0.017 * * *$ & $0.017 * * *$ & $0.017 * * *$ & $0.018 * * *$ & $0.057 * * *$ & $-0.126 * * *$ \\
Tertiary & $(0.005)$ & $(0.002)$ & $(0.002)$ & $(0.002)$ & $(0.004)$ & $(0.005)$ \\
& $0.231 * * *$ & -0.003 & $0.053 * *$ & 0.0007 & $-0.028 * * *$ & $-0.253 * * *$ \\
2008 & $(0.007)$ & $(0.002)$ & $(0.007)$ & $(0.002)$ & $(0.004)$ & $(0.005)$ \\
& $0.431 * * *$ & -0.004 & $0.080 * * *$ & $-0.031 * * *$ & $-0.094 * * *$ & $-0.382 * * *$ \\
2009 & $(0.007)$ & $(0.003)$ & $(0.007)$ & $(0.003)$ & $(0.006)$ & $(0.007)$ \\
2010 & -0.011 & -0.004 & 0.005 & -0.004 & $0.017 * * *$ & -0.004 \\
& $(0.012)$ & $(0.004)$ & $(0.004)$ & $(0.005)$ & $(0.006)$ & $(0.010)$ \\
2011 & $-0.089 * * *$ & $-0.016 * * *$ & 0.002 & -0.002 & $0.129 * * *$ & $-0.024 * *$ \\
& $(0.011)$ & $(0.004)$ & $(0.004)$ & $(0.004)$ & $(0.006)$ & $(0.010)$ \\
& $-0.128 * * *$ & -0.002 & -0.003 & $-0.007 *$ & $0.123 * * *$ & $0.017 *$ \\
& $(0.011)$ & $(0.004)$ & $(0.004)$ & $(0.004)$ & $(0.006)$ & $(0.009)$ \\
\hline
\end{tabular}

Source: SILC longitudinal dataset, 2007-2011.Notes: sample size 31409. Non-professional self-employment includes also family workers. 
Table 7. Labour market transition probabilities - six states

A. All individuals

\begin{tabular}{|c|c|c|c|c|c|c|}
\hline & EP & ET & ESFP & ESFNP & $\mathrm{U}$ & $\mathrm{N}$ \\
\hline & \multicolumn{6}{|c|}{2007 to 2008} \\
\hline $\mathrm{EP}$ & 85.25 & 1.64 & 2.28 & 0.82 & 4.19 & 5.83 \\
\hline ET & 42.03 & 14.49 & 0.00 & 1.45 & 26.09 & 15.94 \\
\hline ESFP & 19.57 & 2.17 & 65.22 & 2.17 & 4.35 & 6.52 \\
\hline ESFNP & 15.48 & 3.57 & 0.00 & 67.86 & 3.57 & 9.52 \\
\hline $\mathrm{U}$ & 20.56 & 7.48 & 0.00 & 2.80 & 44.86 & 24.30 \\
\hline \multirow[t]{2}{*}{$\mathrm{N}$} & 14.02 & 1.89 & 0.19 & 0.57 & 3.03 & 80.30 \\
\hline & \multicolumn{6}{|c|}{2008 to 2009} \\
\hline $\mathrm{EP}$ & 78.66 & 0.99 & 0.86 & 0.73 & 14.05 & 4.71 \\
\hline ET & 36.15 & 13.85 & 3.85 & 3.85 & 26.15 & 16.15 \\
\hline ESFP & 23.42 & 0.90 & 64.86 & 0.90 & 7.21 & 2.70 \\
\hline ESFNP & 9.93 & 1.99 & 2.65 & 68.87 & 11.92 & 4.64 \\
\hline $\mathrm{U}$ & 19.86 & 2.84 & 0.71 & 5.67 & 55.67 & 15.25 \\
\hline \multirow[t]{2}{*}{$\mathrm{N}$} & 8.90 & 2.20 & 0.62 & 2.56 & 12.95 & 72.78 \\
\hline & \multicolumn{6}{|c|}{2009 to 2010} \\
\hline EP & 80.80 & 1.88 & 1.17 & 0.74 & 8.56 & 6.85 \\
\hline ET & 33.33 & 24.24 & 1.01 & 3.03 & 24.24 & 14.14 \\
\hline ESFP & 23.81 & 0.00 & 56.46 & 4.76 & 5.44 & 9.52 \\
\hline ESFNP & 10.60 & 2.76 & 0.00 & 59.45 & 11.52 & 15.67 \\
\hline $\mathrm{U}$ & 18.17 & 7.97 & 0.39 & 2.04 & 52.58 & 18.85 \\
\hline \multirow[t]{2}{*}{$\mathrm{N}$} & 8.21 & 2.07 & 0.27 & 0.67 & 8.41 & 80.39 \\
\hline & \multicolumn{6}{|c|}{2010 to 2011} \\
\hline $\mathrm{EP}$ & 85.47 & 2.87 & 0.94 & 0.49 & 7.01 & 3.23 \\
\hline ET & 41.89 & 27.93 & 0.90 & 1.80 & 22.52 & 4.95 \\
\hline ESFP & 25.00 & 0.00 & 65.79 & 1.32 & 3.95 & 3.95 \\
\hline ESFNP & 14.56 & 3.40 & 0.00 & 62.62 & 11.65 & 7.77 \\
\hline $\mathrm{U}$ & 22.07 & 9.92 & 1.28 & 1.97 & 49.70 & 15.06 \\
\hline $\mathrm{N}$ & 6.67 & 1.80 & 0.33 & 1.26 & 7.71 & 82.23 \\
\hline
\end{tabular}

B. Males

\begin{tabular}{|c|c|c|c|c|c|c|}
\hline & EP & ET & ESFP & ESFNP & $\mathrm{U}$ & $\mathrm{N}$ \\
\hline & \multicolumn{6}{|c|}{2007 to 2008} \\
\hline $\mathrm{EP}$ & 81.47 & 2.65 & 2.84 & 1.32 & 5.86 & 5.86 \\
\hline ET & 36.36 & 15.91 & 0.00 & 0.00 & 31.82 & 15.91 \\
\hline ESFP & 12.50 & 4.17 & 70.83 & 0.00 & 8.33 & 4.17 \\
\hline ESFNP & 18.00 & 4.00 & 0.00 & 70.00 & 2.00 & 6.00 \\
\hline $\mathrm{U}$ & 18.75 & 9.38 & 0.00 & 4.69 & 48.44 & 18.75 \\
\hline \multirow[t]{2}{*}{$\mathrm{N}$} & 10.45 & 1.99 & 0.50 & 1.00 & 3.98 & 82.09 \\
\hline & \multicolumn{6}{|c|}{2008 to 2009} \\
\hline EP & 73.90 & 1.22 & 1.31 & 1.12 & 18.05 & 4.40 \\
\hline ET & 32.18 & 14.94 & 3.45 & 5.75 & 34.48 & 9.20 \\
\hline ESFP & 20.29 & 1.45 & 66.67 & 0.00 & 8.70 & 2.90 \\
\hline ESFNP & 8.51 & 3.19 & 1.06 & 67.02 & 15.96 & 4.26 \\
\hline $\mathrm{U}$ & 14.88 & 3.57 & 0.60 & 5.36 & 63.69 & 11.90 \\
\hline \multirow[t]{2}{*}{$\mathrm{N}$} & 6.25 & 2.64 & 0.48 & 1.68 & 12.50 & 76.44 \\
\hline & \multicolumn{6}{|c|}{2009 to 2010} \\
\hline $\mathrm{EP}$ & 80.56 & 2.38 & 1.35 & 0.95 & 10.48 & 4.29 \\
\hline ET & 32.81 & 29.69 & 1.56 & 4.69 & 21.88 & 9.38 \\
\hline ESFP & 25.30 & 0.00 & 59.04 & 3.61 & 3.61 & 8.43 \\
\hline ESFNP & 11.81 & 1.57 & 0.00 & 65.35 & 10.24 & 11.02 \\
\hline $\mathrm{U}$ & 17.21 & 8.60 & 0.49 & 3.25 & 56.17 & 14.29 \\
\hline \multirow[t]{2}{*}{$\mathrm{N}$} & 5.87 & 2.18 & 0.34 & 1.17 & 8.39 & 82.05 \\
\hline & \multicolumn{6}{|c|}{2010 to 2011} \\
\hline
\end{tabular}




\begin{tabular}{|l|c|c|c|c|c|c|}
\hline EP & 83.70 & 3.73 & 1.52 & 0.84 & 8.30 & 1.90 \\
\hline ET & 37.88 & 32.58 & 0.76 & 2.27 & 24.24 & 2.27 \\
\hline ESFP & 22.62 & 0.00 & 67.86 & 2.38 & 3.57 & 3.57 \\
\hline ESFNP & 14.63 & 3.25 & 0.00 & 63.41 & 12.20 & 6.50 \\
\hline $\mathrm{U}$ & 21.81 & 9.06 & 1.08 & 2.76 & 54.07 & 11.21 \\
\hline $\mathrm{N}$ & 4.93 & 2.19 & 0.41 & 1.10 & 8.90 & 82.47 \\
\hline
\end{tabular}

C. Females

\begin{tabular}{|c|c|c|c|c|c|c|}
\hline & EP & ET & ESFP & ESFNP & $\mathrm{U}$ & $\mathrm{N}$ \\
\hline & \multicolumn{6}{|c|}{2007 to 2008} \\
\hline EP & 88.75 & 0.70 & 1.76 & 0.35 & 2.64 & 5.80 \\
\hline ET & 52.00 & 12.00 & 0.00 & 4.00 & 16.00 & 16.00 \\
\hline ESFP & 27.27 & 0.00 & 59.09 & 4.55 & 0.00 & 9.09 \\
\hline ESFNP & 11.76 & 2.94 & 0.00 & 64.71 & 5.88 & 14.71 \\
\hline $\mathrm{U}$ & 23.26 & 4.65 & 0.00 & 0.00 & 39.53 & 32.56 \\
\hline \multirow[t]{2}{*}{$\mathrm{N}$} & 16.21 & 1.83 & 0.00 & 0.31 & 2.45 & 79.20 \\
\hline & \multicolumn{6}{|c|}{2008 to 2009} \\
\hline EP & 82.69 & 0.79 & 0.47 & 0.40 & 10.67 & 4.98 \\
\hline ET & 44.19 & 11.63 & 4.65 & 0.00 & 9.30 & 30.23 \\
\hline ESFP & 28.57 & 0.00 & 61.90 & 2.38 & 4.76 & 2.38 \\
\hline ESFNP & 12.28 & 0.00 & 5.26 & 71.93 & 5.26 & 5.26 \\
\hline $\mathrm{U}$ & 27.19 & 1.75 & 0.88 & 6.14 & 43.86 & 20.18 \\
\hline \multirow[t]{2}{*}{$\mathrm{N}$} & 10.43 & 1.95 & 0.70 & 3.06 & 13.21 & 70.65 \\
\hline & \multicolumn{6}{|c|}{2009 to 2010} \\
\hline EP & 80.98 & 1.51 & 1.05 & 0.58 & 7.16 & 8.73 \\
\hline ET & 34.29 & 14.29 & 0.00 & 0.00 & 28.57 & 22.86 \\
\hline ESFP & 21.88 & 0.00 & 53.13 & 6.25 & 7.81 & 10.94 \\
\hline ESFNP & 8.89 & 4.44 & 0.00 & 51.11 & 13.33 & 22.22 \\
\hline $\mathrm{U}$ & 19.61 & 7.02 & 0.24 & 0.24 & 47.22 & 25.67 \\
\hline \multirow[t]{2}{*}{$\mathrm{N}$} & 9.75 & 1.99 & 0.22 & 0.33 & 8.42 & 79.29 \\
\hline & \multicolumn{6}{|c|}{2010 to 2011} \\
\hline EP & 86.79 & 2.22 & 0.51 & 0.23 & 6.04 & 4.21 \\
\hline ET & 47.78 & 21.11 & 1.11 & 1.11 & 20.00 & 8.89 \\
\hline ESFP & 27.94 & 0.00 & 63.24 & 0.00 & 4.41 & 4.41 \\
\hline ESFNP & 14.46 & 3.61 & 0.00 & 61.45 & 10.84 & 9.64 \\
\hline $\mathrm{U}$ & 22.39 & 11.00 & 1.54 & 0.97 & 44.21 & 19.88 \\
\hline $\mathrm{N}$ & 7.83 & 1.55 & 0.27 & 1.36 & 6.92 & 82.07 \\
\hline
\end{tabular}

Notes: Sample includes individuals between 16-64 years old. The labour force status is generated as follows. For permanent (EP) and temporary (ET) employees and self-employed and family workers (ESF) the variable employment status was used. Self-employed and family workers are further disaggregated into professional (ESFP) and nonprofessional (ESFNP), where professional refers to occupations 1-3. For unemployed (U) and inactive (N) the information on self-defined current economic status was used. Labour force status is set to missing if both employment status and current economic status are missing. The results have to be interpreted with caution due to the very small number of observations in some categories. 
Table 8. Determinants of transitions, Multinomial logit, marginal effects

a. From dependent permanent employment (EP) to other labour market states - Number of observations: 8641

\begin{tabular}{|c|c|c|c|c|c|}
\hline & $\mathrm{EP}-\mathrm{ET}$ & EP - SEP & EP - SENP & EP - U & EP - N \\
\hline \multirow[t]{2}{*}{ Age } & $-0.0003 * *$ & 0.0001 & 0.0001 & $-0.001 * * *$ & $0.001 * * *$ \\
\hline & $(0.0001)$ & $(0.0001)$ & $(0.0001)$ & $(0.0003)$ & $(0.0002)$ \\
\hline \multirow[t]{2}{*}{ Male } & $0.009 * * *$ & $0.010 * * *$ & $0.006 * * *$ & $0.025 * * *$ & $-0.024 * * *$ \\
\hline & $(0.003)$ & $(0.003)$ & $(0.002)$ & $(0.006)$ & $(0.005)$ \\
\hline \multirow{2}{*}{$\begin{array}{l}\text { Upper } \\
\text { secondary }\end{array}$} & $-0.007 *$ & $0.019 * *$ & $-0.005^{* *}$ & $-0.041 * * *$ & $-0.038 * * *$ \\
\hline & $(0.004)$ & (0.009) & $(0.002)$ & $(0.008)$ & $(0.007)$ \\
\hline \multirow[t]{2}{*}{ Tertiary } & $-0.009 *$ & $0.031 * * *$ & $-0.010 * * *$ & $-0.090 * * *$ & $-0.040 * * *$ \\
\hline & $(0.005)$ & $(0.009)$ & $(0.003)$ & $(0.010)$ & $(0.007)$ \\
\hline \multirow[t]{2}{*}{2008} & -0.006 & $-0.015^{* * *}$ & -0.001 & $0.096 * * *$ & -0.012 \\
\hline & $(0.004)$ & $(0.005)$ & $(0.003)$ & $(0.009)$ & $(0.008)$ \\
\hline \multirow[t]{2}{*}{2009} & $0.003 *$ & $-0.012 * *$ & -0.00001 & $0.048 * * *$ & 0.009 \\
\hline & $(0.004)$ & $(0.005)$ & $(0.003)$ & $(0.008)$ & $(0.009)$ \\
\hline \multirow[t]{2}{*}{2010} & $0.015 * * *$ & $-0.014 * * *$ & -0.002 & $0.030 * * *$ & $-0.030 * * *$ \\
\hline & $(0.005)$ & $(0.005)$ & $(0.003)$ & $(0.008)$ & $(0.008)$ \\
\hline
\end{tabular}

b. From dependent temporary employment (ET) to other labour market states - Number of observations: 462

\begin{tabular}{lccccc}
\hline \hline \multirow{2}{*}{ Age } & ET - EP & ET - SEP & ET - SENP & ET - U & ET - N \\
\cline { 2 - 6 } Male & -0.002 & -0.0006 & -0.00003 & 0.002 & $-0.003 * *$ \\
& $(0.002)$ & $(0.0005)$ & $(0.0006)$ & $(0.002)$ & $(0.001)$ \\
Upper & -0.067 & 0.003 & 0.040 & 0.039 & $-0.123 * * *$ \\
secondary & $(0.045)$ & $(0.011)$ & $(0.027)$ & $(0.041)$ & $(0.029)$ \\
Tertiary & 0.087 & 0.186 & -0.024 & -0.141 & -0.083 \\
& $(4.113)$ & $(8.0594)$ & $(0.114)$ & $(1.378)$ & $(1.119)$ \\
2008 & $\#$ & 0.216 & $\#$ & $\#$ & $\#$ \\
& & $(8.667)$ & & & \\
2009 & -0.069 & $0.039 * *$ & 0.023 & 0.011 & 0.014 \\
& $(0.072)$ & $(0.016)$ & $(0.077)$ & $(0.062)$ & $(0.051)$ \\
2010 & -0.108 & 0.011 & 0.020 & 0.001 & 0.0001 \\
& $(0.075)$ & $(0.011)$ & $(0.077)$ & $(0.065)$ & $(0.054)$ \\
& -0.068 & 0.006 & 0.008 & -0.001 & $-0.099 * *$ \\
& $(0.069)$ & $(0.006)$ & $(0.076)$ & $(0.059)$ & $(0.044)$ \\
\hline
\end{tabular}

c. From professional self-employment (SEP) to other labour market states - Number of observations: 410

\begin{tabular}{lccccc}
\hline \hline \multirow{2}{*}{ Age } & SEP - EP & SEP - ET & SEP - SENP & SEP - U & SEP - N \\
\cline { 2 - 4 } Male & $-0.006 * * *$ & -0.0000 & 0.0006 & -0.0006 & 0.001 \\
& $(0.002)$ & $(0.0002)$ & $(0.0008)$ & $(0.001)$ & $(0.001)$ \\
Upper & -0.092 & 0.060 & -0.012 & -0.002 & -0.005 \\
secondary & $(4.680)$ & $(18.494)$ & $(0.057)$ & $(1.063)$ & $(0.940)$ \\
Tertiary & $\#$ & $\#$ & $\#$ & $\#$ & $\#$ \\
& $-0.345^{* *}$ & -0.145 & $0.442 * * *$ & $0.897 * * *$ & $-0.164 * *$ \\
2008 & $(0.162)$ & $(0.089)$ & $(0.142)$ & $(0.196)$ & $(0.065)$ \\
& 0.033 & $0.022 * *$ & -0.013 & 0.025 & -0.039 \\
2009 & $(0.070)$ & $(0.009)$ & $(0.024)$ & $(0.039)$ & $(0.039)$ \\
& 0.036 & -0.003 & 0.025 & 0.009 & 0.028 \\
2010 & $(0.067)$ & $(0.180)$ & $(0.028)$ & $(0.036)$ & $(0.043)$ \\
& 0.020 & -0.003 & -0.004 & -0.007 & -0.029 \\
& $(0.071)$ & $(0.003)$ & $(0.026)$ & $(0.036)$ & $(0.041)$ \\
\hline
\end{tabular}


d. From non-professional self-employment (SENP) to other labour market states - Number of observations: 611

\begin{tabular}{lccccc}
\hline \hline \multirow{2}{*}{ Age } & SENP - EP & SENP - ET & SENP - SEP & SENP - U & SENP - N \\
\cline { 2 - 6 } Male & $-0.003 * *$ & -0.0003 & -0.0000 & $-0.003 * * *$ & $0.007 * * *$ \\
& $(0.001)$ & $(0.0006)$ & $(0.0004)$ & $(0.001)$ & $(0.001)$ \\
Upper & 0.017 & -0.002 & -0.010 & 0.002 & $-0.082 * * *$ \\
secondary & $(0.027)$ & $(0.014)$ & $(0.008)$ & $(0.025)$ & $(0.024)$ \\
Tertiary & 0.012 & -0.003 & 0.098 & -0.025 & -0.089 \\
2008 & $(1.674)$ & $(0.335)$ & $(16.568)$ & $(2.037)$ & $(0.703)$ \\
& $\#$ & $\#)$ & $\#$ & $\#$ & $\#$ \\
2009 & -0.057 & -0.016 & $0.029 * *$ & $0.084 * *$ & -0.052 \\
& $(0.046)$ & $(0.023)$ & $(0.014)$ & $(0.033)$ & $(0.034)$ \\
2010 & -0.049 & -0.008 & -0.0000 & $0.082 * * *$ & 0.054 \\
& $(0.045)$ & $(0.023)$ & $(0.0001)$ & $(0.030)$ & $(0.038)$ \\
& -0.009 & 0.002 & -0.0000 & $0.077 * *$ & -0.006 \\
& $(0.048)$ & $(0.025)$ & $(0.0001)$ & $(0.032)$ & $(0.037)$ \\
\hline
\end{tabular}

e. From unemployment (U) to other labour market states - Number of observations: 2269

\begin{tabular}{lccccc}
\hline \multirow{3}{*}{ Age } & $\mathrm{U}-\mathrm{EP}$ & $\mathrm{U}-\mathrm{ET}$ & $\mathrm{U}-\mathrm{SEP}$ & $\mathrm{U}-\mathrm{SENP}$ & $\mathrm{U}-\mathrm{N}$ \\
\cline { 2 - 6 } Male & $-0.003 * * *$ & -0.0002 & -0.0000 & 0.0003 & $0.002^{* * *}$ \\
& $(0.001)$ & $(0.0004)$ & $(0.0001)$ & $(0.0003)$ & $(0.0006)$ \\
Upper & -0.006 & -0.002 & 0.002 & $0.026 * * *$ & $-0.103 * * *$ \\
secondary & $(0.017)$ & $(0.012)$ & $(0.004)$ & $(0.009)$ & $(0.016)$ \\
Tertiary & 0.039 & -0.006 & 0.128 & -0.004 & -0.078 \\
& $(3.344)$ & $(1.189)$ & $(13.359)$ & $(0.299)$ & $(1.932)$ \\
2008 & 0.134 & -0.019 & 0.138 & -0.011 & -0.085 \\
& $(3.343)$ & $(1.189)$ & $(13.359)$ & $(0.299)$ & $(1.932)$ \\
2009 & -0.027 & $-0.046 *$ & 0.007 & 0.029 & $-0.080 *$ \\
& $(0.048)$ & $(0.027)$ & $(0.005)$ & $(0.020)$ & $(0.045)$ \\
2010 & -0.051 & 0.004 & $0.004 * *$ & -0.006 & -0.038 \\
& $(0.043)$ & $(0.027)$ & $(0.002)$ & $(0.016)$ & $(0.041)$ \\
& -0.027 & 0.030 & $0.013 * * *$ & -0.006 & $-0.080^{*}$ \\
& $(0.044)$ & $(0.028)$ & $(0.004)$ & $(0.016)$ & $(0.041)$ \\
\hline
\end{tabular}

f. From not-in-the-labour force $(\mathrm{N})$ to other labour market states - Number of observations: 4447

\begin{tabular}{lccccc}
\hline \hline \multirow{3}{*}{ Age } & $\mathrm{N}-\mathrm{EP}$ & $\mathrm{N}-\mathrm{ET}$ & $\mathrm{N}-\mathrm{SEP}$ & $\mathrm{N}-\mathrm{SENP}$ & $\mathrm{N}-\mathrm{U}$ \\
\cline { 2 - 6 } Male & $-0.003^{* * *}$ & $-0.0003 * *$ & 0.0000 & $0.0002 * *$ & $-0.001 * * *$ \\
& $(0.0003)$ & $(0.0001)$ & $(0.0001)$ & $(0.0001)$ & $(0.0003)$ \\
Upper & $-0.026 * * *$ & 0.006 & 0.001 & 0.001 & 0.009 \\
secondary & $(0.009)$ & $(0.004)$ & $(0.002)$ & $(0.001)$ & $(0.009)$ \\
Tertiary & $0.086^{* * *}$ & 0.002 & $0.007 * *$ & 0.006 & 0.040 \\
& $(0.010)$ & $(0.005)$ & $(0.003)$ & $(0.004)$ & $(0.009)$ \\
2008 & $0.168 * * *$ & $0.015 * *$ & 0.006 & -0.020 & $0.036 * *$ \\
& $(0.014)$ & $(0.007)$ & $(0.004)$ & $(0.013)$ & $(0.016)$ \\
2009 & $-0.059 * * *$ & 0.002 & 0.004 & $0.020 * * *$ & $0.098^{* * *}$ \\
& $(0.017)$ & $(0.007)$ & $(0.003)$ & $(0.006)$ & $(0.012)$ \\
2010 & $-0.062 * * *$ & 0.001 & 0.001 & 0.001 & $0.053 * * *$ \\
& $(0.016)$ & $(0.007)$ & $(0.003)$ & $(0.004)$ & $(0.010)$ \\
& $-0.076 * * *$ & -0.0004 & 0.002 & 0.006 & $0.050^{* * *}$ \\
& $(0.017)$ & $(0.007)$ & $(0.002)$ & $(0.004)$ & $(0.011)$
\end{tabular}

Notes: * significant at the 10 percent level, ** significant at the 5 percent level, *** significant at the 1 percent level.

\#: too few observations. 2008: 2008 - 2009; 2009: 2009 - 2010; 2010: 2010 - 2011. 
Table 9. Annual transitions between occupational groups (in percent)

\begin{tabular}{|c|c|c|c|c|}
\hline \multicolumn{5}{|c|}{2007 to 2008} \\
\hline & 1 & 2 & 3 & 4 \\
\hline 1 & 95.39 & 3.29 & 0.44 & 0.88 \\
\hline 2 & 7.82 & 88.27 & 1.68 & 2.23 \\
\hline 3 & 3.33 & 0.95 & 90.95 & 4.76 \\
\hline 4 & 2.36 & 1.35 & 5.05 & 91.25 \\
\hline \multicolumn{5}{|c|}{2008 to 2009} \\
\hline 1 & 97.32 & 1.44 & 0.31 & 0.93 \\
\hline 2 & 3.13 & 95.18 & 0.24 & 1.45 \\
\hline 3 & 1.57 & 1.84 & 92.13 & 4.46 \\
\hline 4 & 0.80 & 1.81 & 1.01 & 96.38 \\
\hline \multicolumn{5}{|c|}{2009 to 2010} \\
\hline 1 & 94.35 & 4.14 & 0.68 & 0.83 \\
\hline 2 & 2.19 & 93.60 & 0.73 & 3.47 \\
\hline 3 & 2.29 & 0.92 & 87.41 & 9.38 \\
\hline 4 & 0.31 & 1.56 & 2.03 & 96.09 \\
\hline \multicolumn{5}{|c|}{2010 to 2011} \\
\hline 1 & 95.50 & 3.12 & 0.58 & 0.80 \\
\hline 2 & 9.36 & 87.36 & 0.16 & 3.12 \\
\hline 3 & 1.69 & 0.42 & 92.41 & 5.49 \\
\hline 4 & 6.49 & 2.25 & 2.78 & 88.48 \\
\hline
\end{tabular}

Source: EU SILC.

Notes: Occupational group1 refers to legislators, senior officials, managers, professionals and associated professionals; Occupational group2 refers to clerks, service workers, shop and sales workers; Occupational group 3 refers to skilled agricultural and fishery workers, craft and related trades workers; Occupational group4 refers to plant and machine operators and assemblers, elementary occupations. 
Table 10. Log real wage regressions with annual job-to-job movements

\begin{tabular}{|c|c|c|c|c|}
\hline & OLS (1) & OLS (2) & OLS (3) & FE (4) \\
\hline \multirow[t]{2}{*}{ Age } & $0.024 * * *$ & $0.020 * * *$ & $0.019 * * *$ & $0.066 * * *$ \\
\hline & $(0.003)$ & $(0.003)$ & $(0.003)$ & $(0.017)$ \\
\hline \multirow[t]{2}{*}{ Age squared } & $-0.000 * * *$ & $-0.000 * * *$ & $-0.000 * * *$ & $-0.001 * * *$ \\
\hline & $(0.000)$ & $(0.000)$ & $(0.000)$ & $(0.000)$ \\
\hline \multirow[t]{2}{*}{ Male } & $0.287 * * *$ & $0.342 * * *$ & $0.344 * * *$ & \\
\hline & $(0.010)$ & $(0.011)$ & $(0.011)$ & \\
\hline \multirow[t]{2}{*}{ Secondary edu. } & $0.250 * * *$ & $0.151 * * *$ & $0.149 * * *$ & -0.026 \\
\hline & $(0.014)$ & $(0.016)$ & $(0.016)$ & $(0.046)$ \\
\hline \multirow[t]{2}{*}{ Tertiary edu. } & $0.835 * * *$ & $0.516 * * *$ & $0.513 * * *$ & -0.049 \\
\hline & $(0.016)$ & $(0.020)$ & $(0.020)$ & $(0.059)$ \\
\hline \multirow{2}{*}{ Job change } & & & $-0.151 * * *$ & -0.007 \\
\hline & & & $(0.018)$ & $(0.021)$ \\
\hline \multirow[t]{2}{*}{2008} & $0.157 * * *$ & $0.165 * * *$ & $0.167 * * *$ & $0.121 * * *$ \\
\hline & $(0.020)$ & $(0.020)$ & $(0.019)$ & $(0.013)$ \\
\hline \multirow[t]{2}{*}{2009} & $0.257 * * *$ & $0.285 * * *$ & $0.282 * * *$ & $0.229 * * *$ \\
\hline & $(0.018)$ & $(0.019)$ & $(0.019)$ & $(0.010)$ \\
\hline \multirow[t]{2}{*}{2010} & $0.126 * * *$ & $0.153 * * *$ & $0.153 * * *$ & $0.091 * * *$ \\
\hline & $(0.018)$ & $(0.018)$ & $(0.018)$ & $(0.008)$ \\
\hline \multirow[t]{2}{*}{2011} & 0.012 & $0.047 *$ & $0.048^{*}$ & \\
\hline & $(0.019)$ & $(0.019)$ & $(0.019)$ & \\
\hline \multirow[t]{2}{*}{ Oc_group2 } & & $-0.339 * * *$ & $-0.334 * * *$ & -0.028 \\
\hline & & $(0.013)$ & $(0.013)$ & $(0.029)$ \\
\hline \multirow[t]{2}{*}{ Oc_group3 } & & $-0.344 * * *$ & $-0.340 * * *$ & 0.007 \\
\hline & & $(0.017)$ & $(0.017)$ & $(0.049)$ \\
\hline \multirow{2}{*}{ Oc_group4 } & & $-0.423 * * *$ & $-0.415 * * *$ & -0.057 \\
\hline & & $(0.016)$ & $(0.017)$ & $(0.036)$ \\
\hline \multirow[t]{2}{*}{ Constant } & $0.545 * * *$ & $0.957 * * *$ & $0.992 * * *$ & $0.109 * * *$ \\
\hline & $(0.056)$ & $(0.060)$ & $(0.060)$ & $(0.396)$ \\
\hline R-squared & 0.20 & 0.25 & 0.26 & \\
\hline Observations & 19332 & 16294 & 16294 & 16294 \\
\hline
\end{tabular}

Notes: Robust standard errors in parentheses. * significant at the 10 percent level, ** significant at the 5 percent level, *** significant at the 1 percent level. Sample includes individuals 16-64 years old not in the armed forces over 2007-

2011. Job change equals 1 if a person changes job since last year. Oc_group1 (reference category) refers to legislators, senior officials, managers, professionals and associated professionals; Oc_group2 refers to clerks, service workers, shop and sales workers ; Oc_group3 refers to skilled agricultural and fishery workers, craft and related trades workers; Oc_group4 refers to plant and machine operators and assemblers, elementary occupations. 
Table 11. Year-by-year coefficients on job change

\begin{tabular}{lccccc}
\hline & 2007 & 2008 & 2009 & 2010 & 2011 \\
\hline Job change & $-0.126 * *$ & $-0.100^{* *}$ & $-0.182^{* * *}$ & $-0.097 * * *$ & $-0.251 * * *$ \\
& $(0.058)$ & $(0.040)$ & $(0.043)$ & $(0.036)$ & $(0.038)$ \\
\hline
\end{tabular}

Notes: Coefficients from pooled OLS regressions are reported. Robust standard errors in parentheses. ** significant at the 5 percent level, *** significant at the 1 percent level. Sample includes individuals 16-64 years old not in the armed forces. All regressions include the same variables as in Table 10. Dependent variable: log of real wages.

Table 12. Coefficients of interaction terms of job change and occupational mobility

\begin{tabular}{lcc}
\hline Job change, & $-0.188^{* * *}$ & -0.027 \\
Upward mobility & $(0.072)$ & $(0.070)$ \\
Job change, & $-0.205^{* * *}$ & $-0.276^{* * *}$ \\
Downward mobility & $(0.072)$ & $(0.072)$ \\
Job change, & $-0.197 * * *$ & $-0.132^{*}$ \\
No mobility & $(0.073)$ & $(0.071)$ \\
Occupations included & No & Yes \\
R-squared & 0.21 & 0.28 \\
Observations & 15303 & 12777 \\
\hline
\end{tabular}

Notes: Coefficients from pooled OLS regressions are reported. Robust standard errors in parentheses. * significant at the 10 percent level, $* *$ significant at the 5 percent level, *** significant at the 1 percent level. Sample includes individuals 16-64 years old not in the armed forces over 2007-2010. All regressions include the same variables as in Table 10. Dependent variable: $\log$ of real wages. 
Figure 1. Annual GDP growth rates of Latvia

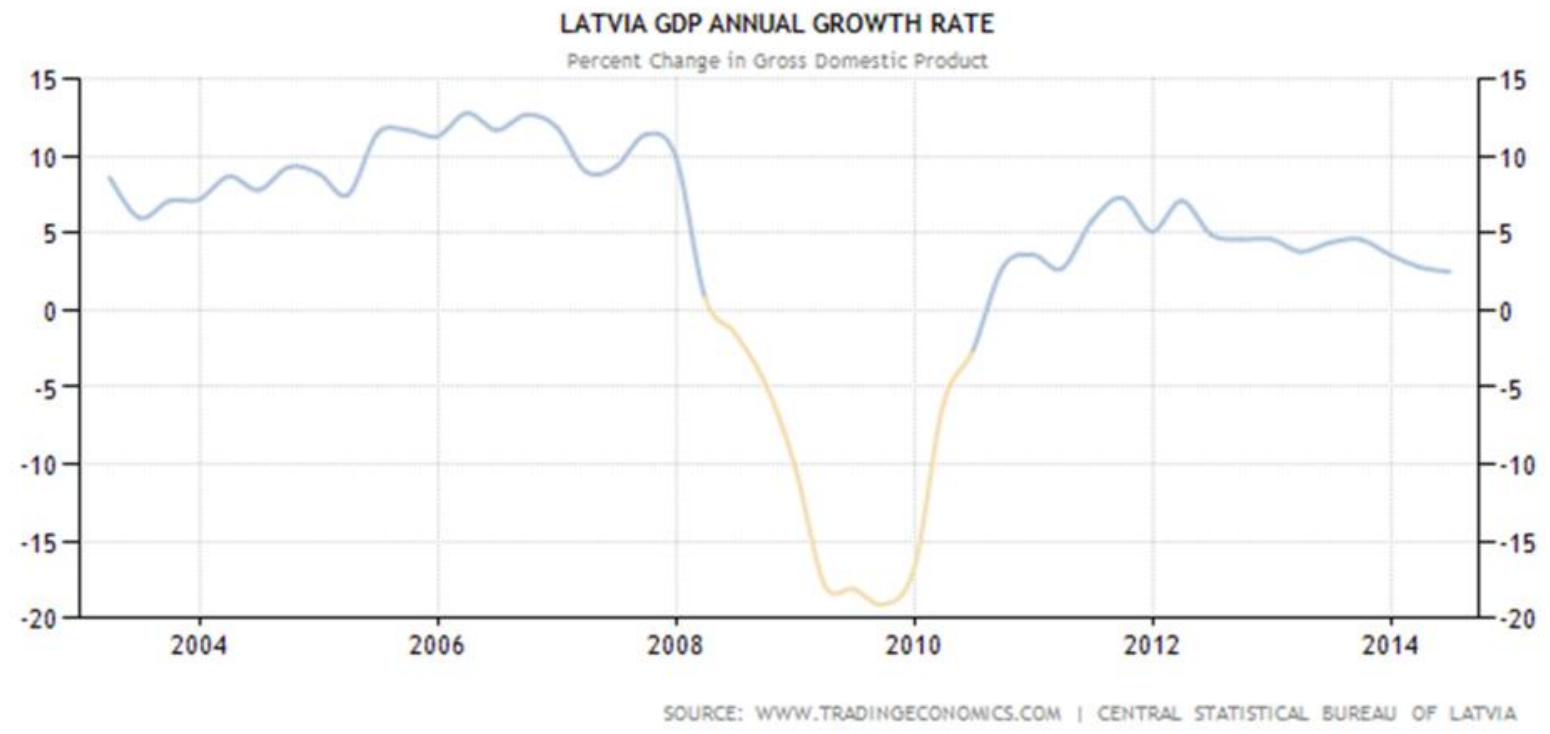

Figure 2. GDP growth in European countries (annual \%)

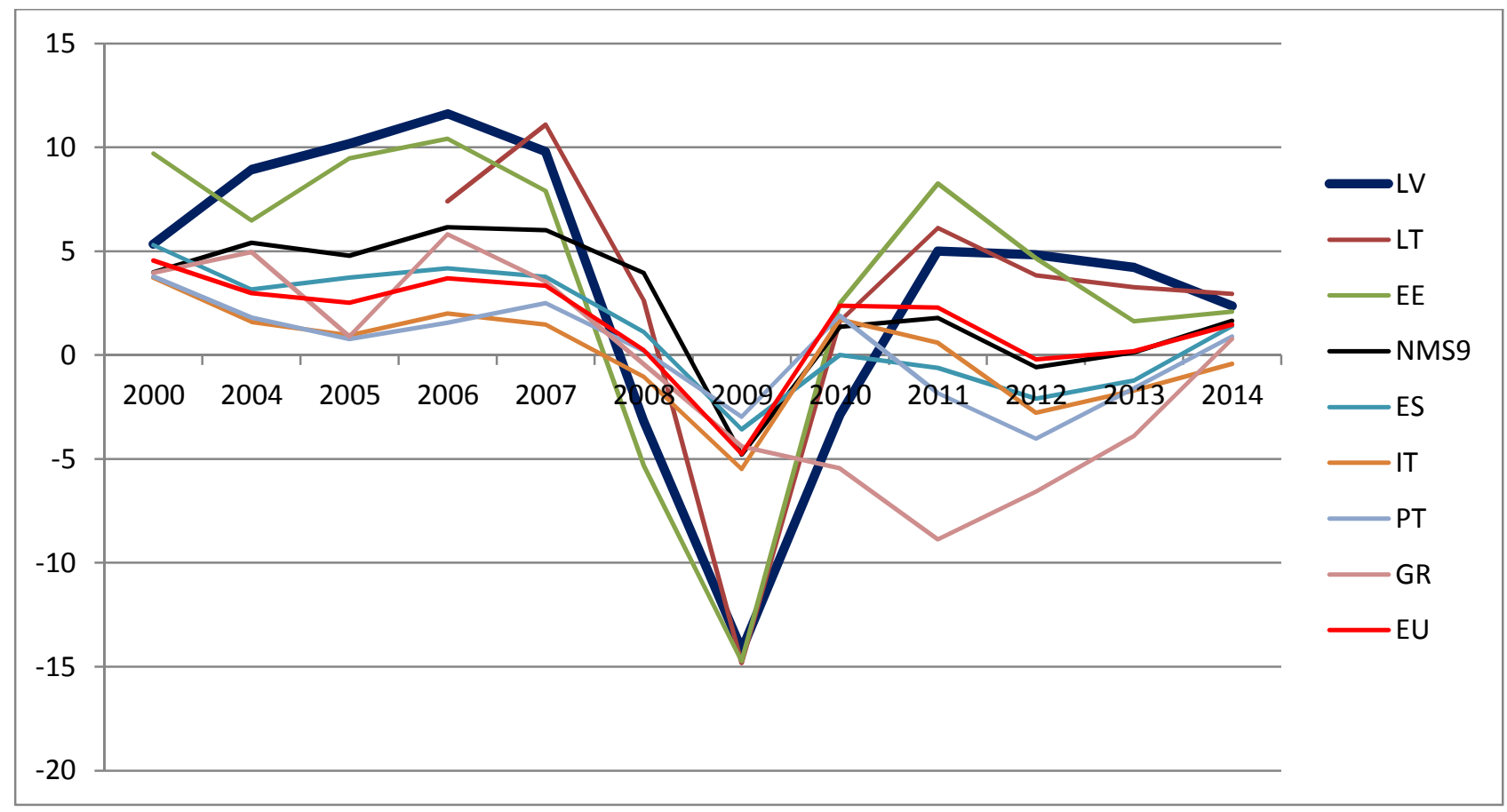

Source: World Bank World Development Indicators.

Notes: Annual percentage growth rate of GDP at market prices based on constant local currency. Aggregates are based on constant 2005 U.S. dollars. NMS stands for the "New Member States" (excluding Malta), EU stands for the remaining "old" EU15 countries (excluding Luxembourg). Simple averages for the NMS and EU are presented. 
Figure 3. Unemployment rate in EU countries and Norway
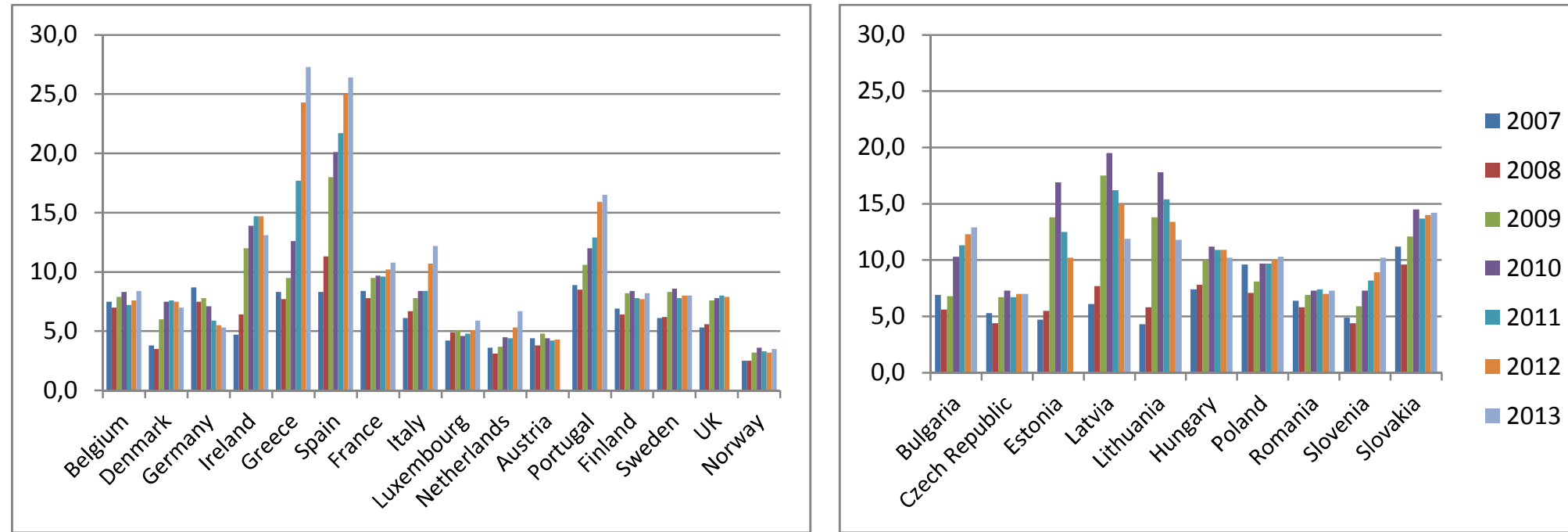

Source: Eurostat.

Figure 4. Youth unemployment rate in EU28 countries

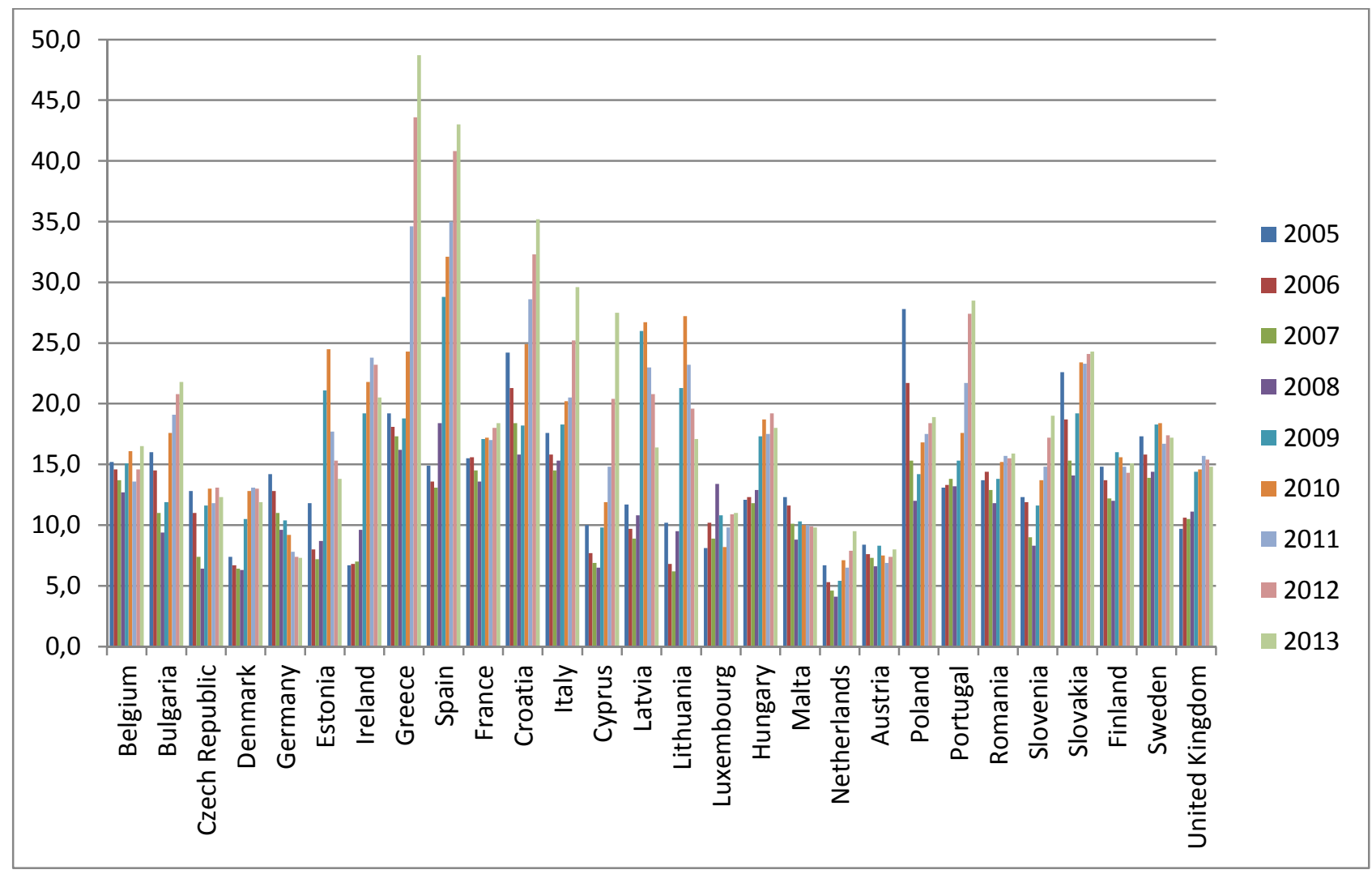

Source: Eurostat. 
Figure 5. Emigration to the UK from the new member states
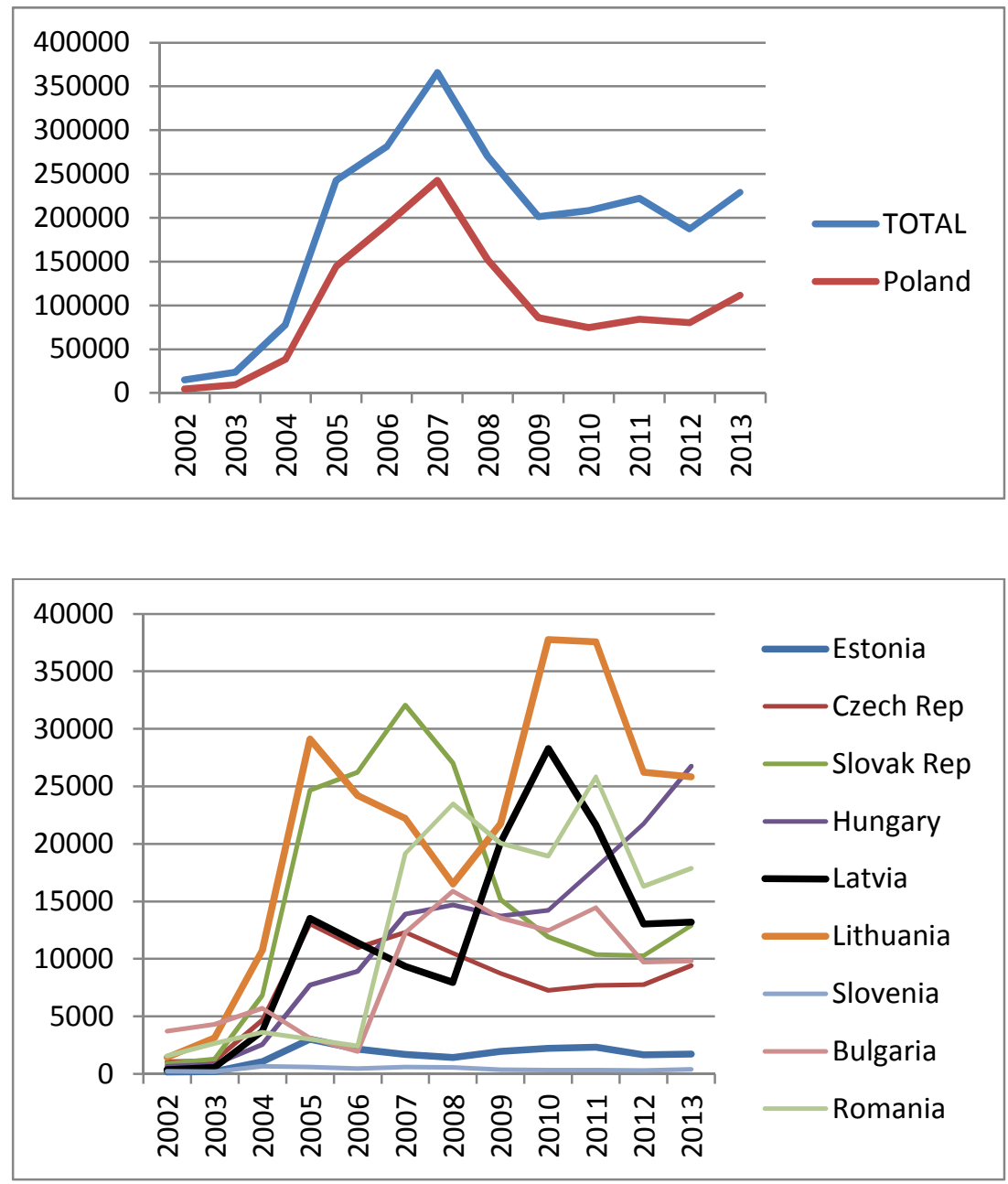

Source: UK Department for Work and Pensions.

Notes: the figure reports National Insurance number allocations to adult overseas nationals entering the UK. 
Figure 6. Emigration from Latvia and the new member states to the UK and unemployment

\section{Latvia}

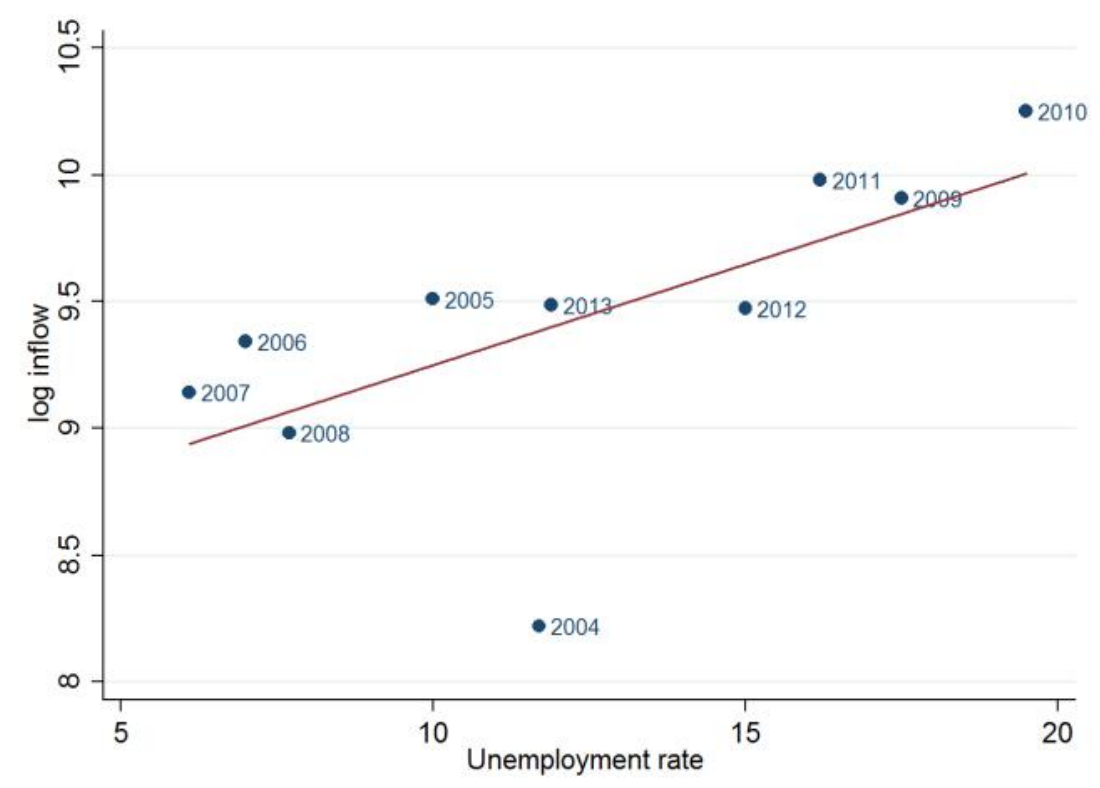

$\underline{\text { All countries }}$

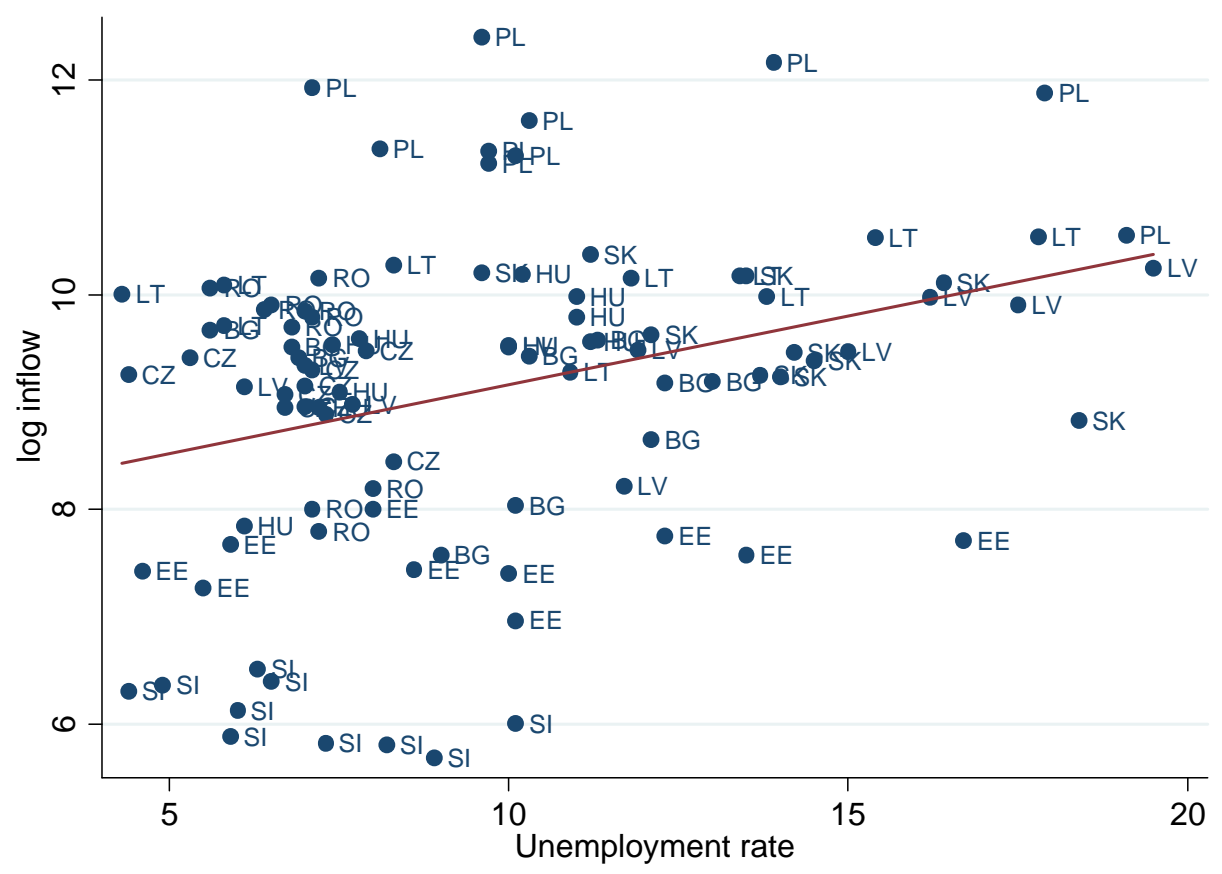

Source: own calculations based on data from Eurostat and UK Department for Work and Pensions 


\section{APPENDIX}

Table A1. Labour market transition probabilities - six states by various demographics a. Age 16-24

\begin{tabular}{|c|c|c|c|c|c|c|}
\hline & EP & ET & ESFP & ESFNP & $\mathrm{U}$ & $\mathrm{N}$ \\
\hline & \multicolumn{6}{|c|}{2007 to 2008} \\
\hline $\mathrm{EP}$ & 78.57 & 2.04 & 0.00 & 0.00 & 7.14 & 12.24 \\
\hline ET & 36.84 & 10.53 & 0.00 & 0.00 & 10.53 & 42.11 \\
\hline ESFNP & 100.00 & 0.00 & 0.00 & 0.00 & 0.00 & 0.00 \\
\hline \multicolumn{7}{|l|}{ ESFP } \\
\hline $\mathrm{U}$ & 27.27 & 9.09 & 0.00 & 9.09 & 27.27 & 27.27 \\
\hline $\mathrm{N}$ & 11.44 & 1.99 & 0.50 & 0.00 & 2.49 & 83.58 \\
\hline & \multicolumn{6}{|c|}{2008 to 2009} \\
\hline EP & 67.98 & 2.96 & 0.00 & 0.49 & 23.15 & 5.42 \\
\hline ET & 29.63 & 7.41 & 7.41 & 0.00 & 18.52 & 37.04 \\
\hline ESFP & 66.67 & 0.00 & 0.00 & 0.00 & 33.33 & 0.00 \\
\hline ESFNP & 0.00 & 0.00 & 0.00 & 33.33 & 66.67 & 0.00 \\
\hline $\mathrm{U}$ & 25.64 & 2.56 & 0.00 & 2.56 & 46.15 & 23.08 \\
\hline \multirow[t]{2}{*}{$\mathrm{N}$} & 6.98 & 2.33 & 0.21 & 0.63 & 13.95 & 75.90 \\
\hline & \multicolumn{6}{|c|}{2009 to 2010} \\
\hline EP & 69.90 & 3.57 & 0.00 & 0.51 & 15.31 & 10.71 \\
\hline ET & 41.18 & 11.76 & 0.00 & 5.88 & 17.65 & 23.53 \\
\hline ESFP & 60.00 & 0.00 & 20.00 & 0.00 & 0.00 & 20.00 \\
\hline ESFNP & 0.00 & 0.00 & 0.00 & 20.00 & 60.00 & 20.00 \\
\hline $\mathrm{U}$ & 15.68 & 6.49 & 0.00 & 0.54 & 44.86 & 32.43 \\
\hline \multirow[t]{2}{*}{$\mathrm{N}$} & 8.21 & 2.84 & 0.00 & 0.60 & 9.25 & 79.10 \\
\hline & \multicolumn{6}{|c|}{2010 to 2011} \\
\hline EP & 77.22 & 5.00 & 0.00 & 0.56 & 11.11 & 6.11 \\
\hline ET & 64.52 & 6.45 & 0.00 & 3.23 & 19.35 & 6.45 \\
\hline ESFP & 100.00 & 0.00 & 0.00 & 0.00 & 0.00 & 0.00 \\
\hline ESFNP & 25.00 & 0.00 & 0.00 & 56.25 & 12.50 & 6.25 \\
\hline $\mathrm{U}$ & 25.16 & 8.18 & 0.00 & 1.26 & 49.06 & 16.35 \\
\hline $\mathrm{N}$ & 7.54 & 1.88 & 0.27 & 0.81 & 7.40 & 82.10 \\
\hline
\end{tabular}

b. Age 25-54

\begin{tabular}{|c|c|c|c|c|c|c|}
\hline & EP & ET & ESFP & ESFNP & $\mathrm{U}$ & $\mathrm{N}$ \\
\hline & \multicolumn{6}{|c|}{2007 to 2008} \\
\hline EP & 86.92 & 1.71 & 2.57 & 0.73 & 4.28 & 3.79 \\
\hline ET & 41.03 & 12.82 & 0.00 & 2.56 & 35.90 & 7.69 \\
\hline ESFP & 20.00 & 2.86 & 65.71 & 0.00 & 5.71 & 5.71 \\
\hline ESFNP & 13.11 & 3.28 & 0.00 & 75.41 & 3.28 & 4.92 \\
\hline $\mathrm{U}$ & 19.44 & 6.94 & 0.00 & 2.78 & 51.39 & 19.44 \\
\hline \multirow[t]{2}{*}{$\mathrm{N}$} & 26.35 & 1.35 & 0.00 & 2.03 & 7.43 & 62.84 \\
\hline & \multicolumn{6}{|c|}{2008 to 2009} \\
\hline EP & 81.70 & 0.71 & 0.94 & 0.77 & 13.58 & 2.30 \\
\hline ET & 39.76 & 16.87 & 3.61 & 3.61 & 28.92 & 7.23 \\
\hline ESFP & 22.35 & 1.18 & 68.24 & 1.18 & 4.71 & 2.35 \\
\hline ESFNP & 9.65 & 2.63 & 2.63 & 71.93 & 11.40 & 1.75 \\
\hline $\mathrm{U}$ & 20.31 & 3.13 & 0.52 & 5.73 & 58.85 & 11.46 \\
\hline \multirow[t]{2}{*}{$\mathrm{N}$} & 14.11 & 3.90 & 0.60 & 4.20 & 19.22 & 57.96 \\
\hline & \multicolumn{6}{|c|}{2009 to 2010} \\
\hline $\mathrm{EP}$ & 83.76 & 1.91 & 1.32 & 0.73 & 8.21 & 4.08 \\
\hline ET & 35.82 & 23.88 & 1.49 & 1.49 & 28.36 & 8.96 \\
\hline ESFP & 26.13 & 0.00 & 56.76 & 5.41 & 5.41 & 6.31 \\
\hline ESFNP & 11.11 & 3.70 & 0.00 & 64.20 & 10.49 & 10.49 \\
\hline $\mathrm{U}$ & 21.79 & 8.62 & 0.45 & 2.57 & 57.34 & 9.23 \\
\hline \multirow[t]{2}{*}{$\mathrm{N}$} & 15.08 & 1.96 & 0.56 & 1.12 & 14.53 & 66.76 \\
\hline & \multicolumn{6}{|c|}{2010 to 2011} \\
\hline EP & 86.51 & 2.81 & 1.19 & 0.53 & 7.08 & 1.89 \\
\hline
\end{tabular}




\begin{tabular}{|l|c|c|c|c|c|c|}
\hline ET & 38.41 & 30.49 & 1.22 & 1.83 & 23.78 & 4.27 \\
\hline ESFP & 27.12 & 0.00 & 66.95 & 1.69 & 3.39 & 0.85 \\
\hline ESFNP & 15.33 & 3.65 & 0.00 & 66.42 & 11.68 & 2.92 \\
\hline $\mathrm{U}$ & 23.42 & 11.03 & 1.73 & 2.11 & 49.69 & 12.02 \\
\hline $\mathrm{N}$ & 10.95 & 2.99 & 1.00 & 1.99 & 15.92 & 67.16 \\
\hline
\end{tabular}

Source: EU SILC longitudinal dataset.

\section{c. Age 55-64}

\begin{tabular}{|c|c|c|c|c|c|c|}
\hline & EP & ET & ESFP & ESFNP & $\mathrm{U}$ & $\mathrm{N}$ \\
\hline & \multicolumn{6}{|c|}{2007 to 2008} \\
\hline EP & 80.00 & 1.43 & 2.14 & 2.14 & 1.43 & 12.86 \\
\hline ET & 75.00 & 0.00 & 0.00 & 0.00 & 25.00 & 0.00 \\
\hline ESFP & 12.50 & 0.00 & 75.00 & 0.00 & 0.00 & 12.50 \\
\hline ESFNP & 18.75 & 0.00 & 0.00 & 50.00 & 6.25 & 25.00 \\
\hline $\mathrm{U}$ & 25.00 & 5.00 & 0.00 & 0.00 & 35.00 & 35.00 \\
\hline \multirow[t]{2}{*}{$\mathrm{N}$} & 5.56 & 2.47 & 0.00 & 0.00 & 0.00 & 91.98 \\
\hline & \multicolumn{6}{|c|}{2008 to 2009} \\
\hline EP & 69.18 & 1.21 & 0.60 & 0.60 & 11.18 & 17.22 \\
\hline ET & 31.25 & 6.25 & 0.00 & 6.25 & 25.00 & 31.25 \\
\hline ESFP & 26.32 & 0.00 & 52.63 & 0.00 & 15.79 & 5.26 \\
\hline ESFNP & 14.81 & 0.00 & 0.00 & 66.67 & 3.70 & 14.81 \\
\hline $\mathrm{U}$ & 17.95 & 0.00 & 0.00 & 10.26 & 41.03 & 30.77 \\
\hline \multirow[t]{2}{*}{$\mathrm{N}$} & 4.33 & 0.33 & 1.00 & 3.33 & 3.67 & 87.33 \\
\hline & \multicolumn{6}{|c|}{2009 to 2010} \\
\hline EP & 70.52 & 0.91 & 1.13 & 1.13 & 5.67 & 20.63 \\
\hline ET & 22.22 & 44.44 & 0.00 & 0.00 & 0.00 & 33.33 \\
\hline ESFP & 11.11 & 0.00 & 59.26 & 3.70 & 3.70 & 22.22 \\
\hline ESFNP & 12.50 & 0.00 & 0.00 & 47.50 & 5.00 & 35.00 \\
\hline $\mathrm{U}$ & 6.62 & 5.88 & 0.00 & 2.21 & 38.24 & 47.06 \\
\hline \multirow[t]{2}{*}{$\mathrm{N}$} & 2.33 & 1.16 & 0.47 & 0.47 & 1.63 & 93.95 \\
\hline & \multicolumn{6}{|c|}{2010 to 2011} \\
\hline EP & 84.60 & 1.79 & 0.22 & 0.22 & 4.69 & 8.48 \\
\hline ET & 40.00 & 30.00 & 0.00 & 0.00 & 20.00 & 10.00 \\
\hline ESFP & 14.81 & 0.00 & 62.96 & 0.00 & 7.41 & 14.81 \\
\hline ESFNP & 9.52 & 4.76 & 0.00 & 50.00 & 9.52 & 26.19 \\
\hline $\mathrm{U}$ & 11.69 & 4.55 & 0.65 & 1.95 & 49.35 & 31.82 \\
\hline $\mathrm{N}$ & 2.58 & 0.74 & 0.00 & 1.11 & 3.51 & 92.07 \\
\hline
\end{tabular}

d. Below upper secondary education

\begin{tabular}{|c|c|c|c|c|c|c|}
\hline & EP & ET & ESFP & ESFNP & $\mathrm{U}$ & $\mathrm{N}$ \\
\hline & \multicolumn{6}{|c|}{2007 to 2008} \\
\hline EP & 76.99 & 2.65 & & 0.88 & 7.96 & 11.50 \\
\hline ET & 38.89 & 16.67 & & 0.00 & 22.22 & 22.22 \\
\hline ESFP & 0.00 & 100.00 & & 0.00 & 0.00 & 0.00 \\
\hline ESFNP & 11.76 & 5.88 & & 70.59 & 0.00 & 11.76 \\
\hline $\mathrm{U}$ & 18.75 & 12.50 & & 3.13 & 34.38 & 31.25 \\
\hline \multirow[t]{2}{*}{$\mathrm{N}$} & 7.24 & 1.36 & & 0.45 & 1.81 & 89.14 \\
\hline & \multicolumn{6}{|c|}{2008 to 2009} \\
\hline EP & 61.64 & 2.62 & 0.00 & 1.64 & 25.90 & 8.20 \\
\hline ET & 19.51 & 7.32 & 0.00 & 7.32 & 46.34 & 19.51 \\
\hline \multicolumn{7}{|l|}{ ESFP } \\
\hline ESFNP & 2.78 & 2.78 & 0.00 & 61.11 & 19.44 & 13.89 \\
\hline $\mathrm{U}$ & 11.39 & 3.80 & 0.00 & 7.59 & 59.49 & 17.72 \\
\hline $\mathrm{N}$ & 3.70 & 1.96 & 0.43 & 1.52 & 10.43 & 81.96 \\
\hline & \multicolumn{6}{|c|}{2009 to 2010} \\
\hline EP & 71.82 & 1.72 & 0.00 & 1.72 & 15.12 & 9.62 \\
\hline ET & 4.35 & 26.09 & 0.00 & 8.70 & 43.48 & 17.39 \\
\hline ESFP & 33.33 & 0.00 & 33.33 & 0.00 & 0.00 & 33.33 \\
\hline
\end{tabular}




\begin{tabular}{|l|c|c|c|c|c|c|}
\hline ESFNP & 9.80 & 1.96 & 0.00 & 50.98 & 13.73 & 23.53 \\
\hline $\mathrm{U}$ & 14.38 & 7.69 & 0.00 & 2.34 & 54.18 & 21.40 \\
\hline $\mathrm{N}$ & 3.35 & 2.23 & 0.00 & 0.64 & 7.66 & 86.12 \\
\hline & \multicolumn{7}{|c|}{$\mathbf{2 0 1 0}$ to $\mathbf{2 0 1 1}$} \\
\hline $\mathrm{EP}$ & 76.21 & 4.18 & 0.32 & 1.29 & 13.83 & 4.18 \\
\hline $\mathrm{ET}$ & 37.25 & 21.57 & 0.00 & 3.92 & 29.41 & 7.84 \\
\hline ESFP & 0.00 & 0.00 & 100.00 & 0.00 & 0.00 & 0.00 \\
\hline ESFNP & 21.43 & 4.76 & 0.00 & 45.24 & 19.05 & 9.52 \\
\hline $\mathrm{U}$ & 14.74 & 10.88 & 0.00 & 1.75 & 56.84 & 15.79 \\
\hline $\mathrm{N}$ & 2.84 & 0.90 & 0.00 & 0.60 & 5.07 & 90.60 \\
\hline
\end{tabular}

a) Upper secondary education

\begin{tabular}{|c|c|c|c|c|c|c|}
\hline & EP & ET & ESFP & ESFNP & $\mathrm{U}$ & $\mathrm{N}$ \\
\hline & \multicolumn{6}{|c|}{2007 to 2008} \\
\hline $\mathrm{EP}$ & 86.67 & 1.46 & 1.46 & 1.14 & 4.07 & 5.20 \\
\hline ET & 43.75 & 12.50 & 0.00 & 3.13 & 28.13 & 12.50 \\
\hline ESFP & 14.29 & 0.00 & 76.19 & 0.00 & 4.76 & 4.76 \\
\hline ESFNP & 16.67 & 1.85 & 0.00 & 66.67 & 3.70 & 11.11 \\
\hline $\mathrm{U}$ & 24.07 & 3.70 & 0.00 & 1.85 & 46.30 & 24.07 \\
\hline \multirow[t]{2}{*}{$\mathrm{N}$} & 15.71 & 1.90 & 0.48 & 0.95 & 3.33 & 77.62 \\
\hline & \multicolumn{6}{|c|}{2008 to 2009} \\
\hline EP & 79.22 & 0.73 & 0.58 & 0.65 & 14.46 & 4.36 \\
\hline ET & 44.78 & 11.94 & 4.48 & 2.99 & 20.90 & 14.93 \\
\hline ESFP & 22.81 & 0.00 & 64.91 & 1.75 & 5.26 & 5.26 \\
\hline ESFNP & 12.62 & 0.97 & 3.88 & 69.90 & 10.68 & 1.94 \\
\hline $\mathrm{U}$ & 22.94 & 2.35 & 0.59 & 5.29 & 54.71 & 14.12 \\
\hline \multirow[t]{2}{*}{$\mathrm{N}$} & 9.45 & 1.89 & 0.84 & 3.78 & 14.08 & 69.96 \\
\hline & \multicolumn{6}{|c|}{2009 to 2010} \\
\hline EP & 80.73 & 1.98 & 0.99 & 0.81 & 9.25 & 6.23 \\
\hline ET & 43.86 & 15.79 & 0.00 & 1.75 & 24.56 & 14.04 \\
\hline ESFP & 22.67 & 0.00 & 54.67 & 8.00 & 4.00 & 10.67 \\
\hline ESFNP & 10.07 & 3.36 & 0.00 & 62.42 & 11.41 & 12.75 \\
\hline $\mathrm{U}$ & 17.66 & 8.15 & 0.51 & 2.04 & 55.35 & 16.30 \\
\hline \multirow[t]{2}{*}{$\mathrm{N}$} & 8.84 & 1.31 & 0.65 & 0.82 & 7.69 & 80.69 \\
\hline & \multicolumn{6}{|c|}{2010 to 2011} \\
\hline $\mathrm{EP}$ & 84.93 & 2.97 & 0.77 & 0.47 & 7.77 & 3.08 \\
\hline ET & 41.86 & 31.78 & 0.00 & 1.55 & 21.71 & 3.10 \\
\hline ESFP & 26.67 & 0.00 & 58.67 & 2.67 & 5.33 & 6.67 \\
\hline ESFNP & 12.75 & 2.68 & 0.00 & 67.11 & 10.07 & 7.38 \\
\hline $\mathrm{U}$ & 22.19 & 9.57 & 0.97 & 1.94 & 49.38 & 15.95 \\
\hline $\mathrm{N}$ & 6.46 & 2.07 & 0.37 & 2.07 & 7.92 & 81.12 \\
\hline
\end{tabular}

b) Tertiary education

\begin{tabular}{|l|c|c|c|c|c|c|}
\hline & EP & ET & ESFP & ESFNP & U & N \\
\hline & \multicolumn{7}{|c|}{$\mathbf{2 0 0 7}$ to 2008 } \\
\hline EP & 88.97 & 0.38 & 5.70 & 0.00 & 1.14 & 3.80 \\
\hline ET & 66.67 & 33.33 & 0.00 & 0.00 & 0.00 & 0.00 \\
\hline ESFP & 19.05 & 0.00 & 66.67 & 4.76 & 4.76 & 4.76 \\
\hline ESFNP & 0.00 & 0.00 & 0.00 & 100.00 & 0.00 & 0.00 \\
\hline $\mathrm{U}$ & 20.00 & 20.00 & 0.00 & 0.00 & 40.00 & 20.00 \\
\hline $\mathrm{N}$ & 25.64 & 5.13 & 0.00 & 0.00 & 0.00 & 69.23 \\
\hline & \multicolumn{7}{|c|}{$\mathbf{2 0 0 8}$ to 2009 } \\
\hline EP & 86.42 & 0.65 & 1.80 & 0.49 & 7.04 & 3.60 \\
\hline ET & 42.86 & 28.57 & 9.52 & 0.00 & 4.76 & 14.29 \\
\hline ESFP & 24.53 & 1.89 & 64.15 & 0.00 & 9.43 & 0.00 \\
\hline
\end{tabular}




\begin{tabular}{|c|c|c|c|c|c|c|}
\hline ESFNP & 8.33 & 8.33 & 0.00 & 83.33 & 0.00 & 0.00 \\
\hline $\mathrm{U}$ & 24.14 & 3.45 & 3.45 & 3.45 & 51.72 & 13.79 \\
\hline $\mathrm{N}$ & 26.17 & 1.87 & 0.93 & 0.93 & 12.15 & 57.94 \\
\hline & \multicolumn{6}{|c|}{2009 to 2010} \\
\hline EP & 84.06 & 1.75 & 1.75 & 0.33 & 5.02 & 7.10 \\
\hline ET & 35.29 & 52.94 & 5.88 & 0.00 & 0.00 & 5.88 \\
\hline ESFP & 23.53 & 0.00 & 60.29 & 1.47 & 7.35 & 7.35 \\
\hline ESFNP & 17.65 & 0.00 & 0.00 & 58.82 & 5.88 & 17.65 \\
\hline $\mathrm{U}$ & 28.83 & 7.21 & 0.00 & 1.80 & 39.64 & 22.52 \\
\hline \multirow[t]{2}{*}{$\mathrm{N}$} & 23.97 & 2.48 & 0.00 & 0.00 & 7.44 & 66.12 \\
\hline & \multicolumn{6}{|c|}{2010 to 2011} \\
\hline EP & 88.99 & 2.16 & 1.47 & 0.29 & 3.93 & 3.15 \\
\hline ET & 48.72 & 25.64 & 5.13 & 0.00 & 12.82 & 7.69 \\
\hline ESFP & 24.32 & 0.00 & 71.62 & 0.00 & 2.70 & 1.35 \\
\hline ESFNP & 15.38 & 7.69 & 0.00 & 61.54 & 7.69 & 7.69 \\
\hline $\mathrm{U}$ & 35.21 & 7.75 & 5.63 & 2.11 & 39.44 & 9.86 \\
\hline $\mathrm{N}$ & 16.48 & 2.84 & 1.14 & 0.00 & 7.95 & 71.59 \\
\hline
\end{tabular}

Source: EU SILC longitudinal dataset.

Notes: The labour force status is generated as follows. For permanent (EP) and temporary (ET) employees and selfemployed and family workers (ESF) the variable employment status was used. Self-employed and family workers are further disaggregated into professional (ESFP) and non-professional (ESFNP), where professional refers to occupations 1-3. For unemployed $(\mathrm{U})$ and inactive $(\mathrm{N})$ the information on self-defined current economic status was used. Labour force status is set to missing if both employment status and current economic status are missing. The results have to be interpreted with caution due to the very small number of observations in some categories. 


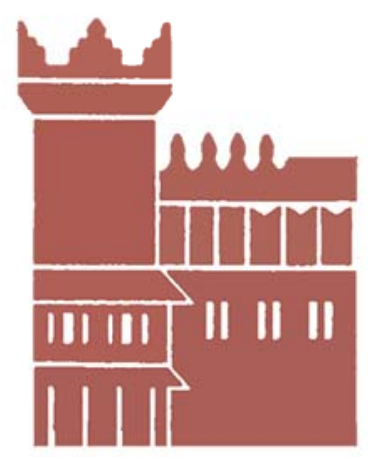

Alma Mater Studiorum - Università di Bologna DEPARTMENT OF ECONOMICS

Strada Maggiore 45

40125 Bologna - Italy

Tel. +39051 2092604

Fax +390512092664

http://www.dse.unibo.it 